\title{
Access to reproductive health and HIV services among young mothers in Tanzania
}

\author{
Francis Obare \\ Population Council \\ Annette Almeida \\ George Odwe \\ Population Council \\ Jamilla Mwanga \\ Chi-Chi Undie \\ Population Council
}

See next page for additional authors

Follow this and additional works at: https://knowledgecommons.popcouncil.org/departments_sbsr-rh

Part of the Demography, Population, and Ecology Commons, Family, Life Course, and Society Commons, International Public Health Commons, Maternal and Child Health Commons, and the Women's Health Commons How does access to this work benefit you? Let us know!

\section{Recommended Citation}

Obare, Francis, Annette Almeida, George Odwe, Jamilla Mwanga, Chi-Chi Undie, Maurice Hiza, and Feddy Mwanga. 2017. "Access to reproductive health and HIV services among young mothers in Tanzania." Dar es Salaam: EngenderHealth, Population Council, and Ministry of Health and Social Welfare. 


\section{Authors}

Francis Obare, Annette Almeida, George Odwe, Jamilla Mwanga, Chi-Chi Undie, Maurice Hiza, and Feddy Mwanga

This report is available at Knowledge Commons: https://knowledgecommons.popcouncil.org/departments_sbsr-rh/ 


\section{ACCESS TO REPRODUCTIVE HEALTH AND HIV SERVICES AMONG YOUNG MOTHERS}

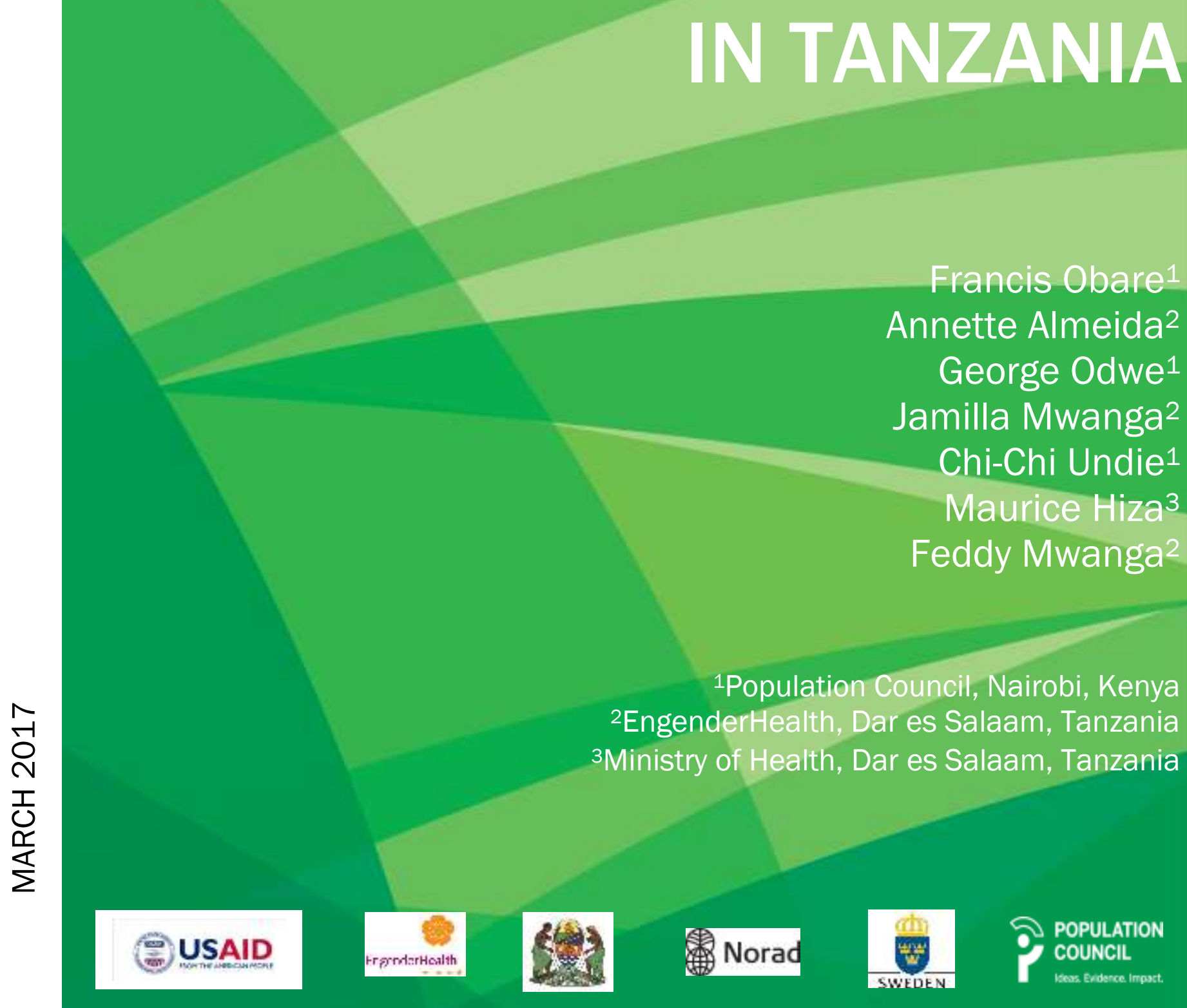




\section{POPULATION COUNCIL \\ Ideas. Evidence. Impact.}

The Population Council confronts critical health and development issues-from stopping the spread of HIV to improving reproductive health and ensuring that young people lead full and productive lives. Through biomedical, social science, and public health research in 50 countries, we work with our partners to deliver solutions that lead to more effective policies, programs, and technologies that improve lives around the world. Established in 1952 and headquartered in New York, the Council is a nongovernmental, non-profit organization governed by an international board of trustees.

Population Council

Avenue 5, $3^{\text {rd }}$ Floor

Rose Avenue

P.O Box 17643-00500

Nairobi

Kenya

E-mail:info.nairobi@popcouncil.org

popcouncil.org

Suggested citation: Obare, Francis, Annette Almeida, George Odwe, Jamilla Mwanga, Chi-Chi Undie, Maurice Hiza, and Feddy Mwanga. 2017. Access to Reproductive Health and HIV Services among Young Mothers in Tanzania. Dar es Salaam: EngenderHealth, Population Council, and Ministry of Health and Social Welfare.

\section{USAID}

This study is made possible by the generous support of the American people through the United States Agency for International Development (USAID). The contents do not necessarily reflect the views of USAID nor the United States Government. 


\section{Table of Contents}

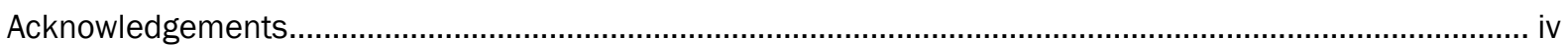

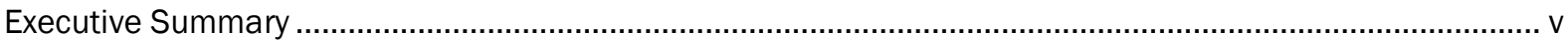

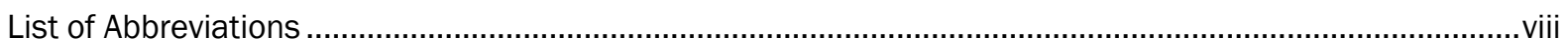

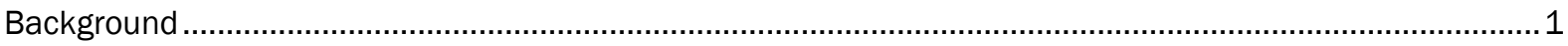

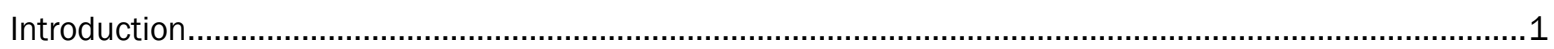

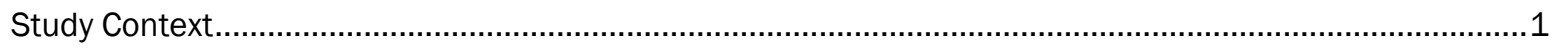

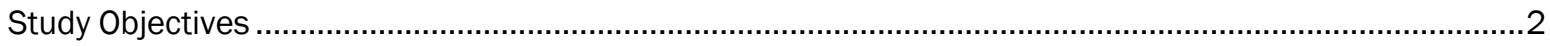

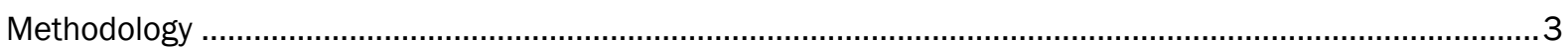

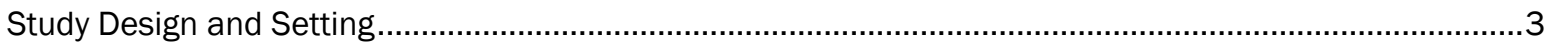

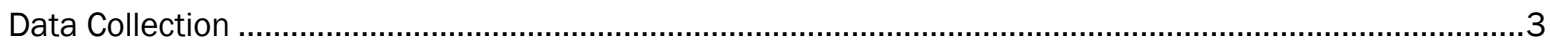

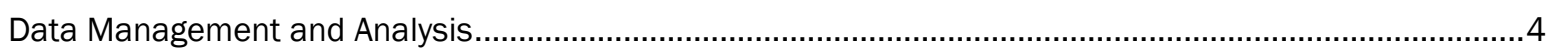

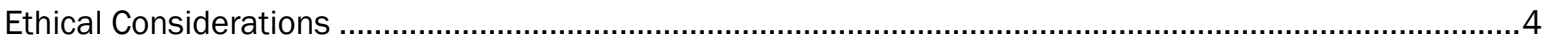

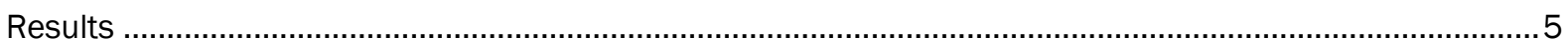

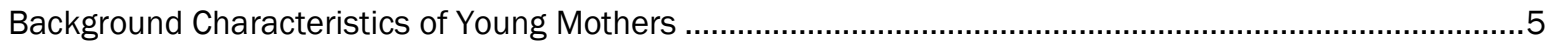

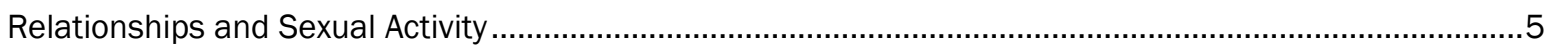

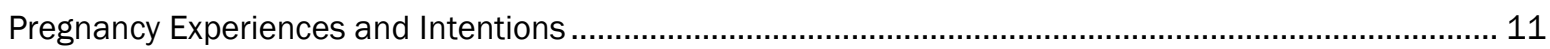

Access to Reproductive Health Information ................................................................................. 12

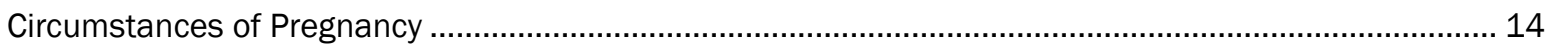

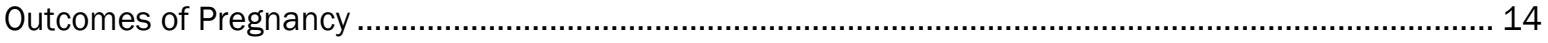

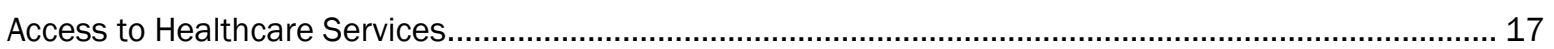

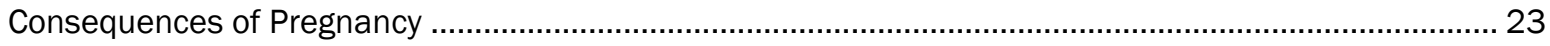

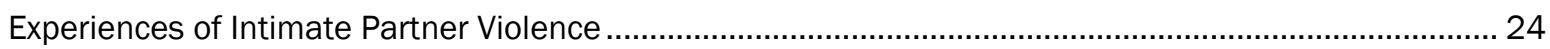

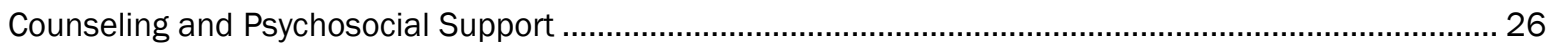

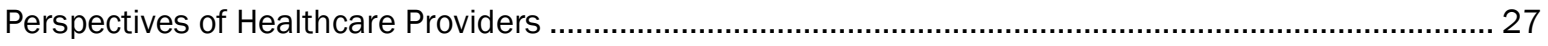

Summary of Findings, Implications and Limitations................................................................................30

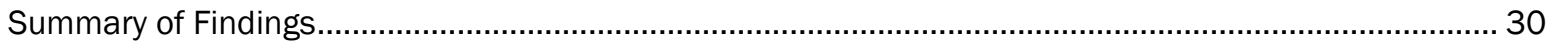

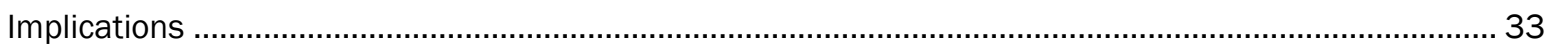

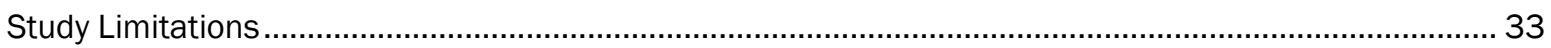

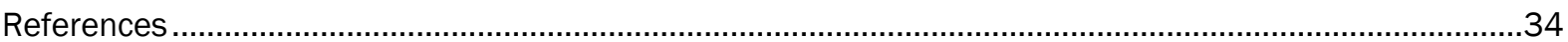




\section{Acknowledgements}

The study that provided the data for this report was conducted under RESPOND Tanzania Project, a five year project (2012-2017) awarded to EngenderHealth by USAID Tanzania (GPO-A-00-08-00007$00)$ to support the Ministry of Health to improve access to quality family planning, comprehensive postabortion care, prevention of mother-to-child transmission of HIV, and gender-based violence services. It was implemented by EngenderHealth and the Population Council in collaboration with the Ministry of Health. The module on intimate partner violence as well as counseling and psychosocial support provided to the young mothers were made possible through financial support from the Regional Team for Sexual and Reproductive Health and Rights, Embassy of Sweden, Lusaka, Zambia.

Esther Ndagaya and Amos Kahwa of the National Institute for Medical Research (NIMR) coordinated the data collection exercise with the assistance of Anthony Kiema of Population Council. Data collection was undertaken by a team of research assistants under the supervision of NIMR. The team comprised Alphonce Kayanda, Amandus Mweyunge, Caroline Kimaro, Caroline Musa, Chacha Manga, Esther Charles, Frank Eric, Godbless Charles, Happiness Sanga, Joymeta Kaihula, Mary-Winnie Nanyaro, Monica Shayo, Saphia Abdallah, Sara Marwerwe, Thomas John, and Victor Minja. We further acknowledge the district health managers in Dar es Salaam and Lindi regions, the service providers, and the young mothers for their role in ensuring the success of the study.

Ethical approval for the study was granted by the Institutional Review Boards of the Population Council and the National Health Research Ethics Review Committee of NIMR in Tanzania. 


\section{Executive Summary}

Many governments of developing countries recognize the importance of addressing adolescent sexual and reproductive health (SRH) needs as a means of breaking the cyclic pattern whereby various vulnerabilities expose young people to the risk of poor SRH outcomes, which in turn exacerbate their vulnerability. The Government of Tanzania, for instance, recognizes the importance of SRH services that are tailored to meet the needs of adolescent mothers, and one of the priorities of the Ministry of Health since 2001 has been to improve reproductive health services for adolescents through partnerships with non-governmental organizations (NGOs) to promote youth-friendly services. There are also favorable policy and legal frameworks for addressing adolescent SRH needs in the country. In spite of the favorable policy and legal environment, little is known about the extent to which adolescent mothers in the country access appropriate reproductive health and HIV services. This report presents findings from a study that examined the experiences of young mothers in Tanzania with accessing reproductive health and HIV services during pregnancy, delivery/pregnancy termination, and postpartum period.

The overall objective of the study was to generate evidence on access to reproductive health and HIV services among young mothers aged 12-19 years in Tanzania in order to inform programming and actions to better meet their needs. It specifically examined their experiences with accessing reproductive health (safe motherhood and contraception) and HIV (testing and counseling, PMTCT, ART and early infant diagnosis) services as well as provider attitudes and practices towards the provision of these services to young mothers. The study was conducted in Temeke District in Dar es Salaam region (urban site) and Nachingwea District in Lindi region (rural site) between October and November 2016. It involved: (1) structured face-to-face interviews with 802 young mothers aged $12-19$ years; (2) in-depth interviews (IDIs) with 26 young mothers (a subset of those who participated in the structured interviews) with poor pregnancy experiences including non-use of services, poor services or poor outcomes); and (3) IDIs with 35 healthcare providers at facilities serving populations in the study settings. Analysis of the quantitative data entailed generating descriptive statistics (frequencies and percentages) while qualitative data were transcribed, typed in Word, translated into English, and analyzed for content.

\section{Key Findings}

- Various vulnerabilities exposed the young mothers to early sexual debut and pregnancy including peer pressure, poor socio-economic conditions, unstable family backgrounds, lack of information on preventive services, early marriage, and cultural rites of initiation for young girls especially in the rural site.

- Majority of the young mothers had first sexual intercourse before age 18 (89\% in urban and $86 \%$ in rural site), with first sex being largely consensual (68\% in urban and $70 \%$ in rural site) in less stable relationships (with steady boyfriend or acquaintance) while most recent sex (last three months) was in more stable relationships (with husband or live-in partner).

- Use of a method to prevent pregnancy was higher during most recent (46\% in urban and $62 \%$ in rural site) than first sexual encounter (19\% in urban and $53 \%$ in rural site). However, use of a method to prevent HIV or sexually transmitted infections (STIs) remained low during first (21\% in urban and $37 \%$ in rural site) or most recent sexual encounter (19\% in urban and $16 \%$ in rural site).

- There were variations in methods used during first and most recent sexual activity, with the most commonly used method at first sex being condom (93\% in urban and $70 \%$ in rural site) while the methods commonly used during last sex were condoms (38\% in urban and $24 \%$ in rural site), injectables (33\% in urban and $43 \%$ in rural site), implants (30\% in urban and $36 \%$ in rural site), and pills (11\% in urban and $2 \%$ in rural site).

- Reasons for non-use of a method to prevent pregnancy or infection shifted from largely lack of knowledge (38\% in urban and $29 \%$ in rural site) during first sex to other factors during most recent sex including partner refusal in the urban site (29\%) and desire to get pregnant in the rural site (26\%).

- Although most young mothers had obtained information on prevention of pregnancy (78\% in urban and $85 \%$ in rural site) and HIV/STIs ( $82 \%$ in urban and $70 \%$ in rural site), they were not satisfied with the information they received ( $70 \%$ in urban and $47 \%$ in rural site). The most common source of information 
on the issues was healthcare providers/counselors (62\% in urban and 55\% in rural site), followed by friends or peers (52\% in urban and $33 \%$ in rural site). In addition, the most preferred sources of such information among young mothers in either site were healthcare providers or facilities, which suggests dissatisfaction with information could be more of adequacy than the source.

- Majority of the young mothers got pregnant for the first time before age 18 (70\% in urban and $73 \%$ in rural site), with a higher proportion of pregnancies in urban than rural site being unintended $(79 \%$ in urban and $46 \%$ in rural site). Variations in unintended pregnancy between sites could partly reflect the circumstances in which the pregnancies occurred. Pregnancies to young mothers in the urban site occurred when they were living with relatives (29\%), single biological parents (24\%), both biological parents (22\%) or husband/partner/boyfriend (22\%) while, majority (60\%) of pregnancies to young mothers in the rural site occurred when they were living with husband, partner or boyfriend. In addition, steady boyfriends or fiancés were responsible for 51 percent of the pregnancies in the urban site while husbands or live-in partners were responsible 56 percent of the pregnancies in the rural site.

- Various factors influenced poor pregnancy influenced poor pregnancy outcomes (complications, miscarriage, stillbirth, abortion) among young mothers who had such experiences. These included preexisting health conditions (such HIV infection, STIs, and high blood pressure), psychological stress associated with unintended pregnancy, no or late initiation of clinic visits, delayed decision-making at the household level to seek care (due to lack of resources or influence of grandparents), intimate partner violence, suspicion of foul play in cases of extended families, lack of relevant services or supplies at facility, long distance to alternative facilities, poor means of transport (use of motorcycles), poor treatment by providers (especially female nurses), and not being provided with appropriate care.

- Access to reproductive health and HIV services varied by type of care, with service-seeking being high for antenatal care (84\% in urban and $93 \%$ in rural site), health facility delivery $(86 \%$ in urban and $85 \%$ in rural site), skilled delivery care ( $86 \%$ in urban and $85 \%$ in rural site), delivery complications $(62 \%$ in urban and $85 \%$ in rural site), and health check-up for the baby (93\% in urban and $82 \%$ in rural site). Care-seeking was lower for PMTCT services (34\% in urban and 52\% in rural site), health check-up for the mother after delivery or pregnancy termination (57\% in urban and $46 \%$ in rural site) and HIV testing for baby HIV (45\% in urban and 38\% in rural site), with three percent of babies in the urban site and one percent of those in the rural site whose mothers shared test results being HIV-positive.

- Factors influencing young mothers' access to reproductive health or HIV services included lack of information on available services, circumstances in which the pregnancy occurred (such as forced sex or very young age) which led to feeling of embarrassment, being disowned by parents or partner, poor socio-economic conditions, the requirement at the facility to be accompanied by a partner, abrupt or early occurrence of pregnancy wastage (abortion, miscarriage or stillbirth occurring too soon after conception), and perceived poor treatment by healthcare providers. Other factors included feeling of embarrassment, partner refusal, delays in decision-making to seek care, distance to facility (especially in the rural site), lack of supplies or services at the facility, and not considering the health condition a serious issue. Being HIV-negative and lack of awareness about HIV status were additional reasons for not obtaining PMTCT services while abrupt labor or labor occurring at night or during weekends when facilities were closed were other reasons for not seeking delivery care.

- Pregnancies to young mothers were more likely to result in negative than positive consequences in cases where mothers reported experiencing life changes. These included worsening of economic status; worsening of health status; and being mocked by family members, friends or neighbors. Only a small fraction of pregnancies to young mothers in either site resulted in positive life changes such as improvements in health or economic status. In addition, being disowned by family members or partner, loss of sense of worth, dropping out of school, psychological stress, and worsening socio-economic conditions were some of the consequences of getting pregnant at an early age.

- Majority of young mothers (63\% in urban and $67 \%$ in rural site) reported experiencing intimate partner violence during pregnancy although few sought help (37\% in urban and $29 \%$ in rural site) while about half (51\%) in urban and a similar proportion in rural site) did not seek help from anywhere. The most common sources for those sought help were family members, relatives or in-laws (79\% in urban and $91 \%$ in rural site) and friends or neighbors (30\% in urban and $11 \%$ in rural site). Reasons for not seeking help included not considering the experience a serious matter (50\% in urban and $52 \%$ in rural site), 
being too scared or ashamed (23\% in urban and $21 \%$ in rural site), not thinking that it was important or it would help ( $18 \%$ in urban and $21 \%$ in rural site), and other reasons such as not seeing the need (9 cases), lack of someone or place to seek help from (6 cases), enduring the experience or feeling that it was normal (6 cases), and settling the matter among themselves ( 5 cases).

- Providers employed various strategies to reach young people in general and young mothers in particular with reproductive health and HIV information and services. The strategies included separating the young people into groups based on age and tailoring the services appropriately; devising friendly ways of relating to them; initiating specific activities for young people to keep them busy (such as youth clubs); providing testing and pregnancy prevention information and services through outreach in the community and in schools; creating separate time for young people (e.g. outside of working hours or workplaces); door-to-door visits by home-based caregivers (HBCs); and engaging parents/guardians.

\section{Implications}

- The vulnerabilities that expose young people to early sexual debut, early pregnancy, and the risk of HIV infection suggest the need for reaching them with appropriate information before they start engaging in risky sexual behavior. One strategy which some of the healthcare providers alluded to is to target them while they are still in school. Such a strategy requires creating strong linkages between the education health sectors in order to ensure that provision of information in schools is by professionals given that teachers may be ill-equipped to offer accurate information.

- Individual-level factors that contribute to non-use of services and poor pregnancy outcomes among young mothers such as lack of awareness about available services, low risk perceptions regarding the chances of getting pregnant or being infected, psychological stress resulting from experiencing unintended pregnancy, and feelings of embarrassment and loss of sense of self-worth can be addressed through appropriate information, education and communication (IEC) campaigns in communities and health facilities.

- Non-use of services and poor pregnancy outcomes among young mothers that result from householdlevel influences such as poverty, unstable families, and intimate partner violence suggest the need for a combination of strategies that involve community sensitization and investments geared towards improving livelihoods at the local level.

- Facility-level influences on use of services and pregnancy outcomes among young mothers such as inconvenient times, requirement for clients to be accompanied by their partners or parents/guardians, stock-outs of medicines and supplies, poor interpersonal relations on the part of providers, inadequate space, and limited human resources require interventions aimed at strengthening the health systems to adequately respond to service needs of young people. 


\section{List of Abbreviations}

\begin{tabular}{|c|c|}
\hline AIDS & Acquired Immune Deficiency Syndrome \\
\hline ART & Antiretroviral Treatment \\
\hline СТC & Counseling and Testing \\
\hline EID & Early Infant Diagnosis \\
\hline HBC & Home-based Care \\
\hline HIV & Human Immunodeficiency Virus \\
\hline HTC & HIV Testing and Counseling \\
\hline IDIs & In-depth Interviews \\
\hline IPV & Intimate Partner Violence \\
\hline IUCD & Intrauterine Contraceptive Device \\
\hline NBS & National Bureau of Statistics \\
\hline NGO & Non-governmental Organization \\
\hline NIMR & National Institute for Medical Research \\
\hline PMTCT & Prevention of Mother-to-Child Transmission \\
\hline $\mathrm{RCH}$ & Reproductive and Child Health \\
\hline $\mathrm{SRH}$ & Sexual and Reproductive Health \\
\hline STI & Sexually Transmitted Infection \\
\hline TDHS & Tanzania Demographic and Health Survey \\
\hline UNAIDS & Joint United Nations Programme on HIV/AIDS \\
\hline WHO & World Health Organization \\
\hline
\end{tabular}




\section{Background}

\section{Introduction}

In many developing countries, adolescents aged 10-19 years are vulnerable to early and unintended pregnancies mainly due to unplanned and unprotected sexual intercourse as well as early marriage (llika and Anthony 2004; Manzini 2001; Okereke 2010; WHO 2011a). In settings with high prevalence of sexually transmitted infections (STIs) including HIV, unprotected sexual intercourse and early marriage further predispose adolescents to the risk of contracting the diseases (Clark 2004; Luke 2003). Adolescent girls are particularly vulnerable to the risk of unplanned pregnancy and STI/HIV infection because of gender norms that perpetuate poor sexual negotiations (McCleary-Sills et al. 2013; Varga 2003). In sub-Saharan Africa, effective response to the challenge of adolescent pregnancy is hampered by several factors including contradictory socio-cultural norms in some communities that on the one hand promote early marriage and on the other discourage adolescent sexuality and early pregnancy; weak healthcare systems; and reproductive health services that are in most cases not oriented towards adequately meeting the needs of adolescents (Katz and Naré 2002; Tylee et al. 2007; Varga 2003; Warenius et al. 2006; Wood and Jewkes 2006; Wright et al. 2006). These factors may further determine whether pregnant adolescent girls access appropriate reproductive healthcare services including safe motherhood services (antenatal care, skilled attendance during delivery and postnatal care), HIV testing and counseling (HTC) during pregnancy as well as prevention of mother-to-child transmission (PMTCT) of HIV, antiretroviral treatment (ART) and early infant diagnosis (EID) for those who are HIV-positive.

Without appropriate care, adolescent pregnancies can have adverse outcomes such as miscarriage, unsafe abortion, obstructed labor, pre-eclampsia, and other complications which can result in long-term morbidity or even death (Becher et al. 2004; Reynolds et al. 2006). These outcomes are likely to exert even a greater burden on the healthcare systems of many developing countries and result in cyclic patterns whereby services are heavily geared towards addressing the consequences rather than the causes of unintended pregnancies among adolescents. Many governments of developing countries therefore recognize the importance of addressing adolescent sexual and reproductive health (SRH) needs as a means of breaking the cycle. The Government of Tanzania, for instance, recognizes the importance of SRH services that are tailored to meet the needs of adolescent mothers, and one of the priorities of the Ministry of Health since 2001 has been to improve reproductive health services for adolescents through partnerships with nongovernmental organizations (NGOs) to promote youth-friendly services (Aarø et al. 2006; Ubora wa Afya kwa Familia Duniani 2001). There are also favorable policy and legal frameworks for addressing adolescent SRH needs in the country including the Sexual Offences Special Provisions Act of 1998, the 2001 National Policy on HIV/AIDS, the 2006 National Population Policy, and the 2007 National Youth Development Policy. In spite of the favorable policy and legal environment, little is known about the extent to which adolescent mothers in Tanzania access appropriate reproductive health and HIV services (Hokororo et al. 2015). This report presents findings from a study that examined the experiences of young mothers in Tanzania with accessing reproductive health and HIV services during pregnancy, delivery/pregnancy termination, and postpartum period. Throughout this report, the term young mothers is used to refer to adolescent girls aged 12-19 years who had ever been pregnant regardless of the outcome of the pregnancy.

\section{Study Context}

It was estimated that as of mid-2014, the population of Tanzania had reached 51 million people representing an increase of about 6 million people from the 2012 census level (National Bureau of Statistics [NBS] 2012; Population Reference Bureau 2014). Females comprised 51 percent of the total population in 2012. Nearly half $(47 \%)$ of the female population was of reproductive age (15-49 years), 23 percent were aged 10-19 years while 10 percent were aged 15-19 years (NBS 2012). Estimates from the 2010 Tanzania Demographic and Health Survey (TDHS) show that 23 percent of adolescent girls aged 15-19 years had begun childbearing (NBS and ICF Macro 2011; Population Council et al. 2015). The proportion of adolescent girls that had begun childbearing was higher in rural than urban areas (26\% and $15 \%$ respectively; NBS and ICF Macro 2011). 
There were also regional variations in the proportion of adolescent girls that had begun childbearing with the prevalence being highest in Western (30\%), Lake (29\%) and Southern (26\%) regions and lowest in Northern $(16 \%)$ and Eastern (18\%) regions (NBS and ICF Macro 2011). Prevalence of adolescent pregnancy was more than eight times higher among those with no education than among those with secondary and above level of education (52\% and 6\% respectively; NBS and ICF Macro 2011).

As already noted, early sexual debut, early marriage and non-use of contraception are some of the factors contributing to adolescent pregnancy in developing countries (llika and Anthony 2004; Manzini 2001; Okereke 2010; WHO 2011a). In Tanzania, estimates from the 2010 TDHS show that 45 percent of adolescent girls aged 15-19 years had ever had sexual intercourse with the median age at first sexual intercourse among women aged 20-49 years being 17 years (NBS and ICF Macro 2011). Similarly, 20 percent of adolescent girls aged 15-19 years had ever been married i.e. married or lived together with a man as if married, separated, divorced or widowed at the time of the survey (NBS and ICF Macro 2011). In contrast, only four percent of boys of similar age groups had ever been married (NBS and ICF Macro 2011). Slightly more than one-third of sexually active (those who had sexual intercourse within one month preceding the survey) unmarried adolescent girls aged 15-19 years (40\%) were using any method of contraception while 35 percent were using a modern method the time of the survey (NBS and ICF Macro 2011). The most commonly used methods were male condoms and injectables.

With respect to consequences of adolescent pregnancy, estimates from the 2010 TDHS show that about one-third (31\%) of the adolescent girls who had ever been pregnant experienced an unintended pregnancy at some point (NBS and ICF Macro 2011). Available evidence indicates that unintended pregnancies result in low of use of maternal and child health services, abortion, miscarriage, and psychosocial problems (Bongaarts and Sinding 2011; Klima 1998; Singh et al. 2010; WHO 2011a, 2011b). Among adolescent girls, unintended pregnancies may further lead to loss of educational opportunities, engagement in child labor to fend for the babies, socio-economic deprivation and gender disparities in access to resources (Biddlecom et al. 2008; Eloundou-Enyegue 2004; Grant and Hallman 2008; Klima 1998; Lloyd et al. 2008; WHO 2011a). It is, for instance, estimated that about 23 percent of all maternal deaths in Tanzania are among young pregnant girls (Mamboleo 2012). Studies have further shown high prevalence of unsafe abortion among young people in the country (Mamboleo 2012; Rasch and Kipingili 2009). In addition, available estimates indicate that 7,138 adolescent girls from the mainland dropped out of school due to pregnancy in 2012 (Ministry of Education and Vocational Training 2013).

\section{Study Objectives}

The overall objective of the study was to generate evidence on access to reproductive health and HIV services among young mothers aged 12-19 years in Tanzania in order to inform programming and actions to better meet their needs. The specific objectives were:

1) To examine the experiences of young mothers aged 12-19 years (i.e. those who have ever been pregnant) with accessing reproductive health services (safe motherhood and contraception).

2) To examine the experiences of young mothers aged 12-19 years in the country with accessing HIV services including testing and counseling, PMTCT, ART and early infant diagnosis.

3) To examine provider attitudes and practices towards the provision of reproductive health and HIV services to young mothers aged $12-19$ years in the country. 


\section{Methodology}

\section{Study Design and Setting}

The study used a cross-sectional design and was conducted in two purposively identified districts in Tanzania: one urban (Temeke district in Dar es Salaam region) and one rural (Nachingwea district in Lindi region). Both districts have the highest HIV prevalence in their respective regions with prevalence of 9 and 5 percent in Temeke and Nachingwea respectively (UNAIDS 2014).

\section{Data Collection}

Data collection took place between October and November 2016 and involved:

1) Structured face-to-face interviews with young mothers aged $12-19$ years;

2) In-depth interviews (IDIs) with a subset of young mothers with poor pregnancy outcomes; and

3) IDIs with healthcare providers at facilities serving populations in the study settings.

\section{Quantitative Interviews with Young Mothers}

A total of 780 young mothers aged $12-19$ years (310 in the urban and 470 in the rural district) were targeted for inclusion in the study based on the prevalence of adolescent pregnancy in the regions where the districts are located. Interviews were completed with 800 young mothers (328 in the urban and 472 in the rural district). Two interviews in the urban district were partially completed because the environment was not conducive for ensuring confidentiality of information provided. The target age range of 12-19 years was informed by a number of factors. First, estimates from the 2010 TDHS showed that the age at first pregnancy among women of reproductive age (15-49 years) ranged from nine to 40 years with 8 percent of women who had ever been pregnant experiencing their first pregnancy between the ages of nine and 14 years. The age at first pregnancy among adolescent girls 15-19 years old, on the other hand, ranged from 12 to 19 years with 13 percent of the girls who had been pregnant experiencing their first pregnancy between the ages of 12 and 14 years. The target age range therefore reflects the general ages at which adolescent girls in the country get pregnant for the first time. Second, older adolescent girls (15-19 years) who had ever been pregnant are likely to be married while younger ones (12-14 years) are likely to be unmarried. Given that the circumstances of married and unmarried young mothers may be different, capturing the entire age range during which adolescent girls become pregnant for the first time in the country provides information that is relevant for age-appropriate programming since the two groups (married and unmarried young mothers) may require different interventions.

Participants were recruited in two stages. In the first stage, the researchers compiled a list of administrative wards in each district that were served by a health facility. A total of seven wards in the urban district and nine in the rural district were included in the study. In the second stage, research teams worked with community health volunteers in the selected wards to purposively identify households with young mothers. The interviews were conducted in Kiswahili by trained research teams comprising young people after obtaining written informed consent or assent from participants. The interviews captured information on the background characteristics of participants (such as age, education level, marital status, and living arrangements), access to reproductive health information, relationships and sexual activity, and experiences of pregnancy including circumstances before, during and after pregnancy including access to healthcare services and experiences of intimate partner violence (IPV). For young mothers who reported experiencing more than one pregnancy, detailed questions were asked about use of healthcare services as well as experiences of IPV for each of the pregnancies.

\section{In-Depth Interviews with Young Mothers}

Twenty four young mothers reporting poor pregnancy outcomes during quantitative interviews were targeted for in-depth interviews in order to gain a deeper understanding of the factors that facilitate or hinder young mothers' access to appropriate reproductive health and HIV services. Poor pregnancy outcomes were 
defined as not seeking any healthcare services (antenatal, delivery and postnatal care) during a pregnancy; receiving poor quality services; or experiencing abortion, stillbirth or miscarriage. Four young mothers in each of the three categories of pregnancy outcomes (separated by age-two for 12-14 and two for 15-19 years) were targeted in each district for a total of twelve participants. Interviews were completed with 26 mothers (14 in the urban 12 in the rural district), with four of them (all in urban site) being aged between 12-14 years. The interviews were conducted in Kiswahili by research assistants with training in qualitative data collection using a guide with pre-determined themes. The interviews were audio-recorded with consent of participants.

\section{In-depth Interviews with Service Providers}

A total of 36 healthcare providers from 18 purposively selected facilities (nine facilities in each district) were targeted for in-depth interviews to understand the service delivery factors that facilitate or hinder young mothers' access to appropriate reproductive health and HIV services. In each selected facility, one provider from the reproductive and child health $(\mathrm{RCH})$ unit and another from HIV unit were targeted for interview. Interviews were completed with 35 providers aged between 23 and 61 years (17 in urban and 18 in rural site), with 32 of them being female. The providers were purposively identified with the help of facility managers based on their availability and willingness to participate in the study. The interviews were conducted in Kiswahili by the same research assistants who conducted in-depth interviews with young mothers using a guide with pre-determined themes after obtaining written informed consent. The interviews were scheduled when providers were free to avoid interfering with normal service delivery at health facilities and were audio-recorded with the consent of participants.

\section{Data Management and Analysis}

Quantitative interviews with young mothers were conducted using tablets and submitted to a central from where they were downloaded and exported to Stata for analysis. Analysis entailed generating descriptive statistics (frequencies and percentages). Qualitative data from IDIs were transcribed, typed in Word, translated into English, and analyzed for content. Analysis involved identifying common themes based on the interview guides.

\section{Ethical Considerations}

The Institutional Review Board of the Population Council and the National Health Research Ethics Review Committee of the National Institute for Medical Research (NIMR) granted ethical approval for the study. Written informed consent was obtained from all participants aged 18-19 years before conducting interviews. For participants aged 12-17 years, consent was obtained at two levels-the parent or guardian first granted written informed consent while the young mothers provided written assent before conducting the interviews. The study also engaged local counselors (three in each site) to accompany the research teams and offer counseling and psychosocial support to informants who needed the services free of charge as a strategy for minimizing risks associated with potentially sensitive questions to participants. A similar approach has been used as a strategy for minimizing risks in a study on violence against children in Kenya (Republic of Kenya 2012). 


\section{Results}

\section{Background Characteristics of Young Mothers}

Most of the young mothers were aged between 18 and 19 years (75\% in urban and $67 \%$ in rural site), had completed primary level education (54\% in urban and $60 \%$ in rural site), were not attending school at the time of the interview (nearly $100 \%$ in both sites), and belonged to Muslim faith (86\% in urban and $63 \%$ in rural site; Table 1). The proportion of young mothers with secondary level education and above was more than twice higher in the urban than in the rural site (32\% and $14 \%$ respectively). The most commonly mentioned reasons for not currently attending school were poor performance (22\% in urban and $48 \%$ in rural site), lack of fees or learning materials (30\% in urban and $22 \%$ in rural site), completion of a given level of schooling (15\% in urban and $8 \%$ in rural site), and pregnancy or childbirth (16\% in urban and $4 \%$ in rural site).

About one-third (30\%) of young mothers in the urban site lived with other relatives, followed by husband, partner or boyfriend (26\%), single biological parent (23\%), and both biological parents (18\%; Table 1). In contrast, more than half (54\%) of the young mothers in the rural site lived with husband, partner or boyfriend, followed by both biological parents (18\%), single biological parent (14\%), and other relatives (11\%). For young mothers in the urban site who were not living with both biological parents, 38 percent reported that one of their parents was dead, 27 percent indicated that their parents were divorced or separated while 26 percent were double orphans (both parents dead). Majority (48\%) of young mothers in the rural site who were not living with both biological parents reported that their parents were divorced or separated, about one-third $(32 \%)$ indicated that both parents were dead while 18 percent were single orphans (one parent dead). More than half (59\%) of young mothers in the urban site reported that they were unemployed while most (77\%) of those in the rural site indicated that they were engaged in some form of self-employment. However, majority of those in both sites who were not living alone reported that the household's breadwinner was engaged in formal sector employment (55\% in urban and $76 \%$ in rural site).

\section{Relationships and Sexual Activity}

About two-thirds of young mothers in both sites had the first sexual intercourse between the ages of 15 and 17 years (63\% in urban and 66\% in rural site) while 26 percent of those in the urban and 20 percent of those in the rural site had first sexual intercourse between the ages of 11 and 14 years (Table 2). More than twothirds of young mothers in either site had consensual first sex i.e. either or both partners wanted to have sexual intercourse (68\% in urban and $70 \%$ in rural site). The first sexual partner was older than the respondent for 62 and 64 percent of cases in urban and rural sites respectively. In both sites, the first sexual partner was mostly either a steady boyfriend/fiancé (46\% in urban and $38 \%$ in rural site) or friend/acquaintance ( $43 \%$ in urban and $47 \%$ in rural site). The first sexual intercourse resulted in pregnancy for $16 \%$ of young mothers in the urban and seven percent of those in the rural site.

A lower proportion of young mothers in the urban than in the rural site whose first sexual intercourse was not forced or a result of rape used a method to prevent pregnancy (19\% and 53\% respectively) or HIV/sexually transmitted infections-STIs) (21\% in urban and 37\% in rural site; Table 2). The most commonly used method at first sex was condom (93\% in urban and $70 \%$ in rural site), with the source of method largely being shops or pharmacies/drug stores in the urban site (43\% and 39\% respectively) and shops, health facilities or pharmacies/drug stores in the rural site (41\%, 39\% and 19\% respectively). For young mothers in the urban site who used a method at first sex, the decision was mostly a joint one (39\%), made by the respondent (36\%) or the partner (26\%). In the rural site, about half (51\%) of the young mothers who used a method at first sex reported that the decision was theirs, 25 percent indicated that it was joint decision while 20 percent mentioned that their partners made the decision. 
TABLE 1: DISTRIBUTION OF YOUNG MOTHERS BY BACKGROUND CHARACTERISTICS

\begin{tabular}{|c|c|c|c|}
\hline Characteristics & $\begin{array}{r}\text { Urban } \\
(\%)\end{array}$ & $\begin{array}{r}\text { Rural } \\
(\%)\end{array}$ & $\begin{array}{r}\text { Both sites } \\
(\%)\end{array}$ \\
\hline Age group (years) & $(\mathrm{N}=330)$ & $(\mathrm{N}=472)$ & $(\mathrm{N}=802)$ \\
\hline $12-14$ & 0.9 & 1.5 & 1.3 \\
\hline $15-17$ & 23.9 & 31.4 & 28.3 \\
\hline $18-19$ & 75.2 & 67.2 & 70.5 \\
\hline Highest education level & $(\mathrm{N}=330)$ & $(\mathrm{N}=472)$ & $(\mathrm{N}=802)$ \\
\hline None/pre-school & 2.4 & 8.5 & 6.0 \\
\hline Primary incomplete & 12.4 & 17.4 & 15.3 \\
\hline Primary complete & 53.6 & 60.2 & 57.5 \\
\hline Secondary and above & 31.5 & 14.0 & 21.2 \\
\hline Respondent currently attending school & $(\mathrm{N}=322)$ & $(\mathrm{N}=433)$ & $(\mathrm{N}=755)$ \\
\hline No & 99.7 & 99.5 & 99.6 \\
\hline Yes & 0.3 & 0.5 & 0.4 \\
\hline Main reason for not attending school & $(\mathrm{N}=321)$ & $(\mathrm{N}=431)$ & $(\mathrm{N}=752)$ \\
\hline Completed level & 15.0 & 8.1 & 11.0 \\
\hline Lack of fees/materials & 30.2 & 22.3 & 25.7 \\
\hline Parent/guardian died & 1.9 & 0.5 & 1.1 \\
\hline Pregnancy/had child & 16.2 & 4.2 & 9.3 \\
\hline Got married & 0.9 & 3.3 & 2.3 \\
\hline Poor performance & 22.4 & 48.0 & 37.1 \\
\hline Suspended/expelled & 1.6 & 0.5 & 0.9 \\
\hline Illness & 1.9 & 2.6 & 2.3 \\
\hline Domestic/family tasks & 0.3 & 1.4 & 0.9 \\
\hline Punishment/bullying & 0.0 & 0.5 & 0.3 \\
\hline Not interested in school & 6.9 & 2.1 & 4.1 \\
\hline Employment reasons & 0.0 & 0.2 & 0.1 \\
\hline Distance too far & 0.0 & 1.6 & 0.9 \\
\hline Other & 2.8 & 4.9 & 4.0 \\
\hline Usual living arrangements & $(\mathrm{N}=330)$ & $(\mathrm{N}=472)$ & $(\mathrm{N}=802)$ \\
\hline Both biological parents & 18.2 & 18.0 & 18.1 \\
\hline Single biological parent & 22.7 & 14.4 & 17.8 \\
\hline Husband/partner/boyfriend & 26.1 & 54.2 & 42.6 \\
\hline Other relatives & 29.7 & 10.6 & 18.5 \\
\hline Non-relatives/alone & 3.3 & 2.8 & 3.0 \\
\hline Status of biological parents & $(\mathrm{N}=270)$ & $(\mathrm{N}=387)$ & $(\mathrm{N}=657)$ \\
\hline Divorced/separated & 26.7 & 47.6 & 39.0 \\
\hline One parent dead & 37.8 & 18.1 & 26.2 \\
\hline Both parents dead & 25.9 & 32.0 & 29.5 \\
\hline Both parents alive & 9.3 & 2.1 & 5.0 \\
\hline Don't know & 0.4 & 0.3 & 0.3 \\
\hline Respondent's main occupation & $(\mathrm{N}=330)$ & $(\mathrm{N}=472)$ & $(\mathrm{N}=802)$ \\
\hline Unemployed/housewife/student & 59.4 & 10.8 & 30.8 \\
\hline Informal/casual/domestic work & 18.8 & 10.6 & 14.0 \\
\hline Forma sector employment & 2.7 & 1.3 & 1.9 \\
\hline Self-employed & 19.1 & 77.3 & 53.4 \\
\hline Main occupation of breadwinner in householda & $(\mathrm{N}=318)$ & $(\mathrm{N}=458)$ & $(\mathrm{N}=776)$ \\
\hline Unemployed & 17.6 & 2.8 & 8.9 \\
\hline Informal/casual/domestic work & 25.2 & 14.6 & 18.9 \\
\hline Forma sector employment & 55.4 & 75.6 & 67.2 \\
\hline Self-employed & 1.9 & 7.0 & 4.9 \\
\hline Respondent's religion & $(\mathrm{N}=330)$ & $(\mathrm{N}=472)$ & $(\mathrm{N}=802)$ \\
\hline Catholic & 8.2 & 25.9 & 18.6 \\
\hline Protestant/other Christian & 6.4 & 10.6 & 8.9 \\
\hline Muslim & 85.5 & 63.4 & 72.4 \\
\hline No religion & 0.0 & 0.2 & 0.1 \\
\hline
\end{tabular}


TABLE 2: RELATIONSHIPS AND SEXUAL ACTIVITY: FIRST SEXUAL ENCOUNTER

\begin{tabular}{|c|c|c|c|}
\hline Indicator & $\begin{array}{r}\text { Urban } \\
(\%)\end{array}$ & $\begin{array}{r}\text { Rural } \\
(\%)\end{array}$ & $\begin{array}{r}\text { Both sites } \\
(\%)\end{array}$ \\
\hline Age at first sexual intercourse (years) & $(\mathrm{N}=330)$ & $(\mathrm{N}=472)$ & $(\mathrm{N}=802)$ \\
\hline $10-14$ & 25.5 & 19.9 & 22.2 \\
\hline $15-17$ & 63.0 & 66.1 & 64.8 \\
\hline $18-19$ & 7.9 & 4.9 & 6.1 \\
\hline Don't remember & 3.6 & 8.5 & 6.5 \\
\hline No answer & 0.0 & 0.6 & 0.4 \\
\hline Circumstances of first sexual intercourse & $(\mathrm{N}=330)$ & $(\mathrm{N}=472)$ & $(\mathrm{N}=802)$ \\
\hline Forced/raped & 6.4 & 8.5 & 7.6 \\
\hline Tricked & 13.0 & 7.6 & 9.9 \\
\hline Persuaded with money/gifts & 9.4 & 12.5 & 11.2 \\
\hline Respondent wanted to/curiosity & 11.8 & 17.0 & 14.8 \\
\hline Partner wanted to have sex & 6.4 & 4.5 & 5.2 \\
\hline Both wanted to have sex & 49.7 & 48.3 & 48.9 \\
\hline No answer & 3.3 & 1.7 & 2.4 \\
\hline Relative age of first sexual partner & $(\mathrm{N}=330)$ & $(\mathrm{N}=472)$ & $(\mathrm{N}=802)$ \\
\hline Younger & 0.3 & 1.5 & 1.0 \\
\hline Same age & 30.0 & 30.1 & 30.1 \\
\hline Older & 61.8 & 64.2 & 63.2 \\
\hline Much older & 7.9 & 3.8 & 5.5 \\
\hline No answer & 0.0 & 0.4 & 0.3 \\
\hline Relationship to first sexual partner & $(\mathrm{N}=330)$ & $(\mathrm{N}=472)$ & $(\mathrm{N}=802)$ \\
\hline Husband/live-in partner & 7.6 & 10.8 & 9.5 \\
\hline Steady boyfriend/fiancé & 45.5 & 38.1 & 41.2 \\
\hline Friend/acquaintance & 43.3 & 47.0 & 45.5 \\
\hline Stranger & 3.6 & 2.1 & 2.7 \\
\hline Teacher/mentor & 0.0 & 0.4 & 0.3 \\
\hline Other & 0.0 & 1.3 & 0.8 \\
\hline No answer & 0.0 & 0.2 & 0.1 \\
\hline First sexual intercourse resulted in pregnancy & $(N=330)$ & $(\mathrm{N}=472)$ & $(\mathrm{N}=802)$ \\
\hline No & 83.9 & 93.0 & 89.3 \\
\hline Yes & 15.8 & 6.8 & 10.5 \\
\hline No answer & 0.3 & 0.2 & 0.3 \\
\hline $\begin{array}{l}\text { Respondent/partner used a method to prevent pregnancy at } \\
\text { first sexa }\end{array}$ & $\begin{array}{r}18.9 \\
(\mathrm{~N}=281)\end{array}$ & $\begin{array}{r}53.4 \\
(\mathrm{~N}=425)\end{array}$ & $\begin{array}{r}39.7 \\
(\mathrm{~N}=706)\end{array}$ \\
\hline $\begin{array}{l}\text { Respondent/partner used a method to prevent HIV/STI at } \\
\text { first sexa }\end{array}$ & $\begin{array}{r}21.4 \\
(\mathrm{~N}=281)\end{array}$ & $\begin{array}{r}36.5 \\
(\mathrm{~N}=425)\end{array}$ & $\begin{array}{r}30.5 \\
(\mathrm{~N}=706)\end{array}$ \\
\hline Method used at first sex ${ }^{b}$ & $(\mathrm{~N}=70)$ & $(\mathrm{N}=236)$ & $(\mathrm{N}=306)$ \\
\hline Condom & 92.9 & 69.5 & 74.8 \\
\hline Pill & 2.9 & 8.9 & 7.5 \\
\hline Emergency pill & 0.0 & 0.9 & 0.7 \\
\hline Injectables & 2.9 & 30.9 & 24.5 \\
\hline Implants & 0.0 & 1.7 & 1.3 \\
\hline Decision maker to use a method at first sex & $(\mathrm{N}=70)$ & $(\mathrm{N}=236)$ & $(\mathrm{N}=306)$ \\
\hline Respondent & 35.7 & 50.9 & 47.4 \\
\hline Partner & 25.7 & 19.5 & 20.9 \\
\hline Joint decision & 38.6 & 25.4 & 28.4 \\
\hline Relative/friend/neighbor & 0.0 & 3.8 & 2.9 \\
\hline No answer & 0.0 & 0.4 & 0.3 \\
\hline Source of method used at first sexb & $(\mathrm{N}=70)$ & $(\mathrm{N}=236)$ & $(\mathrm{N}=306)$ \\
\hline Health facility & 5.7 & 39.0 & 31.4 \\
\hline Pharmacy/drug shop & 38.6 & 19.1 & 23.5 \\
\hline Shop & 42.9 & 41.1 & 41.5 \\
\hline Friend/peer & 1.4 & 3.8 & 3.3 \\
\hline Other & 8.6 & 1.3 & 2.9 \\
\hline
\end{tabular}


A higher proportion of young mothers in the rural than in the urban areas had sexual intercourse in the past three months preceding the survey (53\% and $19 \%$ respectively; Table 3$)$. In nearly all the cases (98\% in either site), either or both partners to have sexual intercourse. Similar to first sexual intercourse, the last sex was with an older partner ( $70 \%$ and $79 \%$ in urban and rural sites respectively). Unlike first sexual intercourse, half $(50 \%)$ of young mothers in the urban site and 75 percent of those in the rural site had the last sex with a husband or live-in partner. The proportion of young mothers that used a method at last sex to prevent a pregnancy was higher than that at first sex (46\% in urban and $62 \%$ in rural site) while the proportion that used a method to prevent HIV/STIs remained low (19\% in urban and 16\% in rural site). Among young mothers in the urban site who used a method at last sex, the methods commonly used were condoms (38\%), injectables (33\%), implants (30\%), and pills (11\%). In the rural site, the methods commonly used were injectables (43\%), implants (36\%), and condoms (24\%). The decision to use a method at last sex was largely the respondent's (60\% in urban and $46 \%$ in rural site) or made jointly with the partner (35\% in urban and $41 \%$ in rural site) while health facilities were the predominant sources of a method used during last sex (67\% in urban and $84 \%$ in rural site). Only a small fraction of the young mothers reported that they felt pressure from others to have sexual intercourse (11\% in urban and $6 \%$ in rural site), with such pressure mostly coming from friends or peers (77\% in urban and $63 \%$ in rural site), neighbors (23\% in urban and $13 \%$ in rural site), and husband, partner or boyfriend (14\% in urban and $20 \%$ in rural site).

Among young mothers in the urban site who did not use a method to prevent pregnancy or HIV/STIs at first sex, the reasons given for non-use included lack of knowledge of methods (38\%), respondents not thinking that they would get pregnant (35\%), partner refusing to use a method (18\%), and lack of time to prepare (13\%; Figure 1). In the rural site, the most common reasons for non-use were lack of knowledge (29\%) and respondents not thinking that they would get pregnant (12\%; Figure2). Among young mothers in the urban site who did not use a method at last sex, the most common reasons given for non-use were partner refusal (23\%), respondents not thinking that they would get pregnant (21\%), fear of side-effects (12\%), desire to get pregnant (11\%) and other reasons (36\%) largely being that they trusted themselves or their partners. In the rural site, the most common reasons for non-use of a method at last sex were desire to get pregnant (26\%), respondents not thinking that they would get pregnant (25\%), and other reasons (22\%) largely being that they were already pregnant.

\section{FIGURE 1: REASONS FOR NON-USE OF CONTRACEPTION IN URBAN SITE}

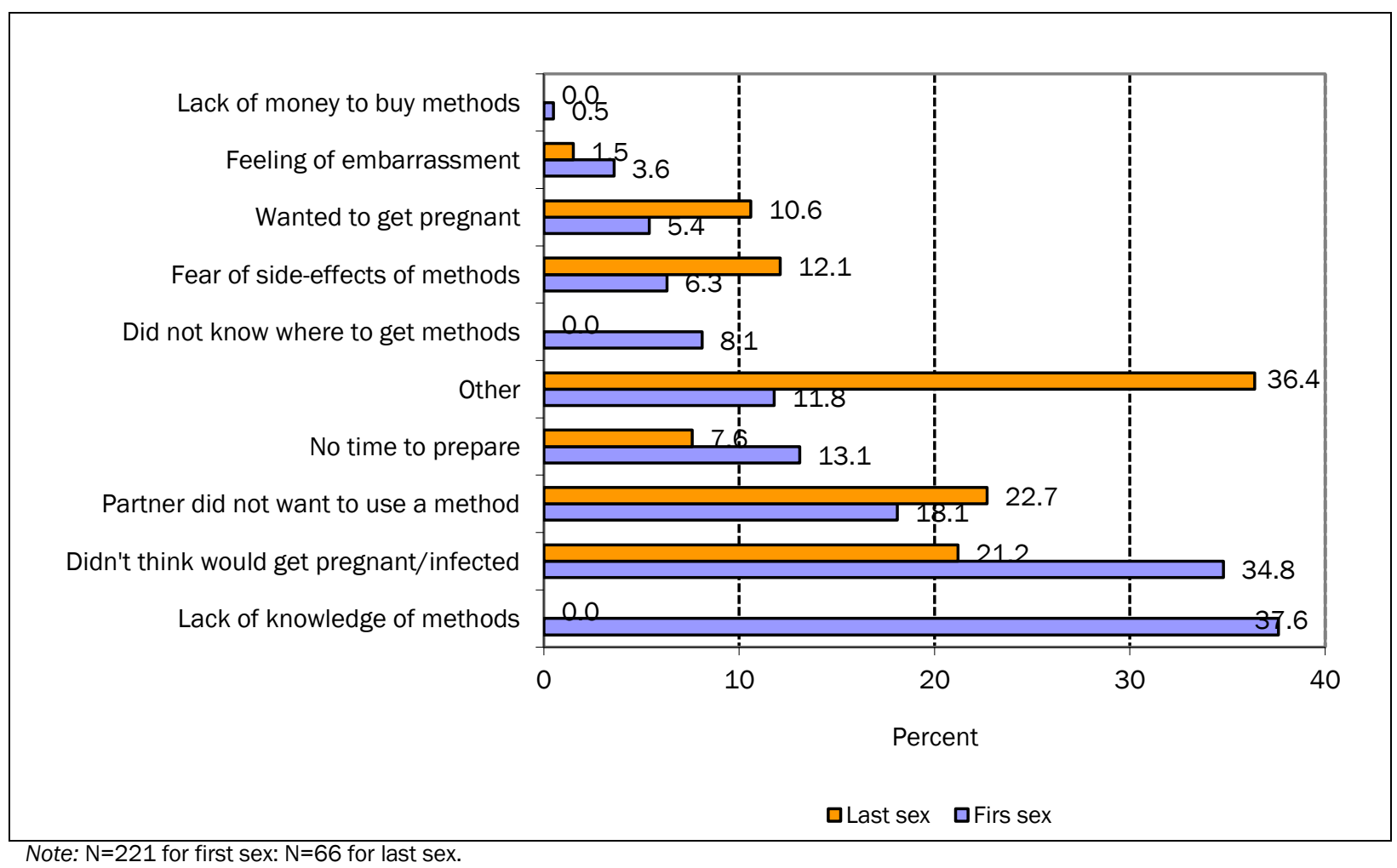


TABLE 3: RELATIONSHIPS AND SEXUAL ACTIVITY: LAST SEXUAL ENCOUNTER

\begin{tabular}{|c|c|c|c|}
\hline Indicator & $\begin{array}{r}\text { Urban } \\
(\%)\end{array}$ & $\begin{array}{r}\text { Rural } \\
(\%)\end{array}$ & $\begin{array}{r}\text { Both } \\
\text { sites } \\
(\%)\end{array}$ \\
\hline Respondent had sexual intercourse last 3 months & $(\mathrm{N}=330)$ & $(\mathrm{N}=472)$ & $(\mathrm{N}=802)$ \\
\hline No & 61.2 & 46.4 & 52.5 \\
\hline Yes & 18.5 & 53.0 & 47.0 \\
\hline No answer & 0.3 & 0.6 & 0.5 \\
\hline Circumstances of last sexual intercourse & $(\mathrm{N}=127)$ & $(\mathrm{N}=250)$ & $(\mathrm{N}=377)$ \\
\hline Forced/raped & 0.8 & 2.0 & 1.6 \\
\hline Tricked & 0.8 & 0.0 & 0.3 \\
\hline Respondent wanted to/curiosity & 3.9 & 3.2 & 3.5 \\
\hline Partner wanted to have sex & 4.7 & 8.0 & 6.9 \\
\hline Both wanted to have sex & 89.0 & 86.8 & 87.5 \\
\hline No answer & 0.8 & 0.0 & 0.3 \\
\hline Relative age of last sexual partner & $(\mathrm{N}=127)$ & $(\mathrm{N}=250)$ & $(\mathrm{N}=377)$ \\
\hline Younger & 0.0 & 0.4 & 0.3 \\
\hline Same age & 25.1 & 16.0 & 18.0 \\
\hline Older & 70.1 & 78.8 & 75.9 \\
\hline Much older & 7.9 & 4.8 & 5.8 \\
\hline Relationship to last sexual partner & $(\mathrm{N}=127)$ & $(\mathrm{N}=250)$ & $(\mathrm{N}=377)$ \\
\hline Husband/live-in partner & 49.6 & 75.2 & 66.6 \\
\hline Steady boyfriend/fiancé & 37.8 & 16.4 & 23.6 \\
\hline Friend/acquaintance & 12.6 & 8.0 & 9.6 \\
\hline Other & 0.0 & 0.4 & 0.3 \\
\hline $\begin{array}{l}\text { Respondent/partner used a method to prevent pregnancy at } \\
\text { last sex }\end{array}$ & $\begin{array}{r}46.0 \\
(N=126)\end{array}$ & $\begin{array}{r}61.6 \\
(N=245)\end{array}$ & $\begin{array}{r}56.3 \\
(\mathrm{~N}=371)\end{array}$ \\
\hline $\begin{array}{l}\text { Respondent/partner used a method to prevent HIV/STI at last } \\
\text { sex }\end{array}$ & $(\mathrm{N}=126)$ & $(\mathrm{N}=245)$ & $(\mathrm{N}=371)$ \\
\hline Method used at last sexa & $(\mathrm{N}=60)$ & $(\mathrm{N}=152)$ & $(\mathrm{N}=212)$ \\
\hline Condom & 38.3 & 24.3 & 28.3 \\
\hline Pill & 11.7 & 2.0 & 4.7 \\
\hline Injectables & 33.3 & 49.3 & 44.8 \\
\hline Implants & 30.0 & 35.5 & 34.0 \\
\hline IUCD/coil/loop & 0.0 & 1.3 & 0.9 \\
\hline Withdrawal & 0.0 & 1.3 & 0.9 \\
\hline Other & 1.7 & 0.0 & 0.5 \\
\hline Decision maker to use a method at last sex & $(\mathrm{N}=60)$ & $(\mathrm{N}=152)$ & $(\mathrm{N}=212)$ \\
\hline Respondent & 60.0 & 46.1 & 50.0 \\
\hline Partner & 3.3 & 10.5 & 8.5 \\
\hline Joint decision & 35.0 & 40.8 & 39.2 \\
\hline Provider/parent/guardian & 1.7 & 2.6 & 2.4 \\
\hline Source of method used at last sexa & $(\mathrm{N}=60)$ & $(\mathrm{N}=152)$ & $(\mathrm{N}=212)$ \\
\hline Health facility & 66.7 & 83.6 & 78.8 \\
\hline Pharmacy/drug shop & 25.0 & 9.2 & 13.7 \\
\hline Shop & 16.7 & 16.5 & 16.5 \\
\hline Friend/peer & 5.0 & 2.0 & 2.8 \\
\hline Other & 3.3 & 0.0 & 0.9 \\
\hline $\begin{array}{l}\text { Respondent feels pressure from others to have sexual } \\
\text { intercourse }\end{array}$ & $\begin{array}{r}10.6 \\
(\mathrm{~N}=330)\end{array}$ & $\begin{array}{r}6.4 \\
(N=472)\end{array}$ & $\begin{array}{r}8.1 \\
(N=802)\end{array}$ \\
\hline Person who puts pressure on respondent to have sex & $(\mathrm{N}=35)$ & $(\mathrm{N}=30)$ & $(\mathrm{N}=65)$ \\
\hline Husband/partner/boyfriend & 14.3 & 20.0 & 16.9 \\
\hline Friends/peers & 77.1 & 63.3 & 70.8 \\
\hline Parent/guardian & 5.7 & 0.0 & 3.1 \\
\hline Uncles/aunts & 2.9 & 0.0 & 1.5 \\
\hline Other relatives & 5.7 & 3.3 & 4.6 \\
\hline Neighbors & 22.9 & 13.3 & 18.5 \\
\hline Other & 2.9 & 0.0 & 1.5 \\
\hline
\end{tabular}




\section{FIGURE 2: REASONS FOR NON-USE OF CONTRACEPTION IN RURAL SITE}

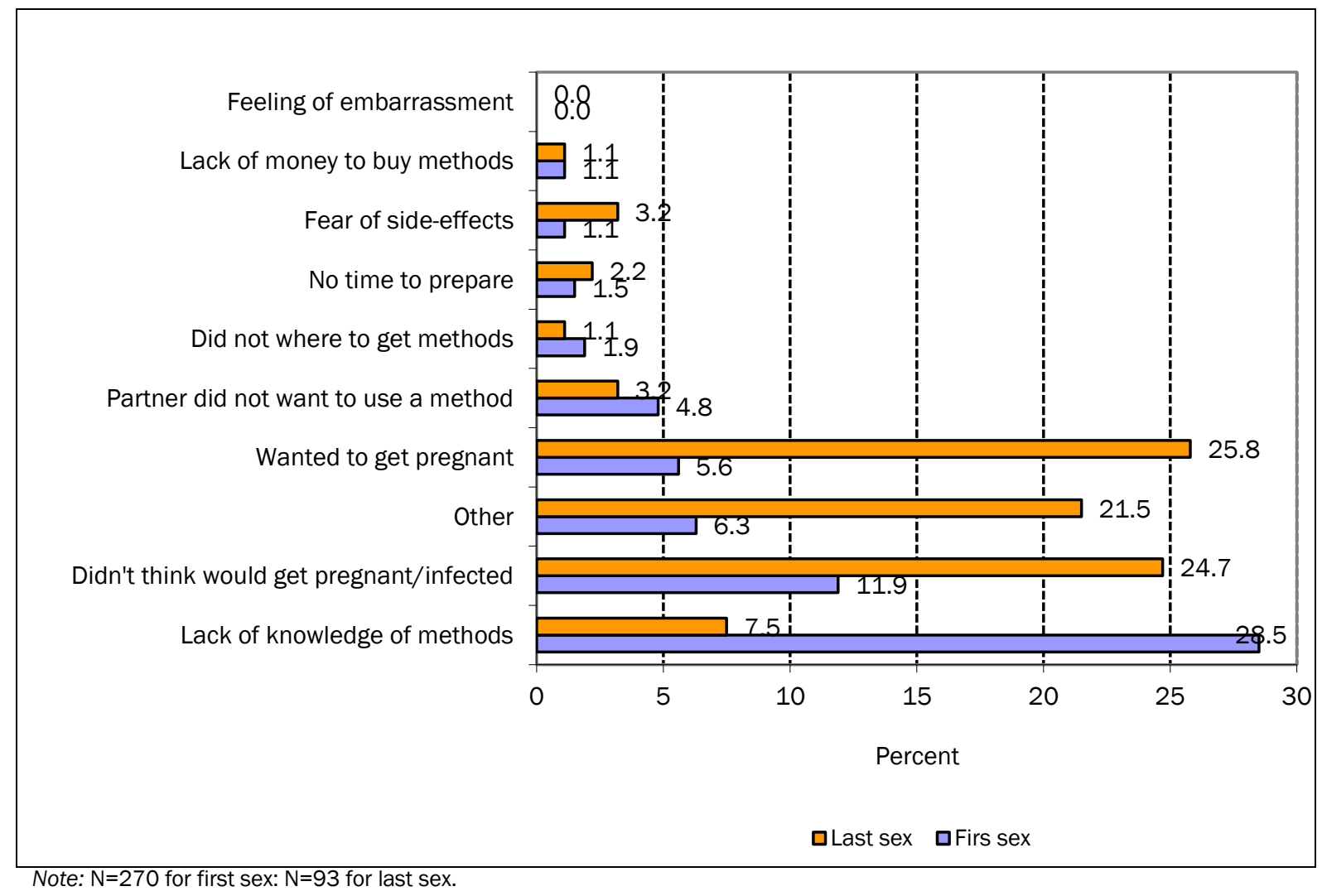

In-depth interviews with young mothers showed that peer pressure, poor socio-economic background, family disruptions (through separation, divorce or death), sexual assault, and being tricked were some of the reasons for engaging in sexual activity at an early age. In addition, misconceptions about contraception (especially among those aged 12-14 years), partner refusal, false promises of marriage, and placing a lot of trust on the partners were some of the reasons for non-use of contraception.

I was convinced... my friends in groups influenced me...Usually we left school early on Fridays. My friends used to spend [on foodstuffs/chips] but I had no money to spend. So they told me to adjust myself...I did not want to be like them but it was hard to stay away from their behaviors...the first day we had sex, I told him to use condoms but he said no. So we had sex two times without using condoms and I became pregnant.

(Young mother, 15-19 years, urban site)

I had never used protection and when I met this fellow he cheated me that he was going to marry me and I got pregnant in the process...When I realized there were changes in my health, my partner and I went to a testing facility... At the testing facility we were told I was three months pregnant.

(Young mother, 15-19 years, rural site) 


\section{Pregnancy Experiences and Intentions}

Most of the young mothers had been pregnant once ( $87 \%$ in urban and $92 \%$ in rural site; Table 4). Majority got pregnant for the first time between the ages of 15 and 17 years (58\% in urban and $67 \%$ in rural site) while the proportion that got pregnant at ages 11-14 years was twice as high in the urban than in the rural site ( $12 \%$ and $6 \%$ respectively). Most young mothers intended to have more children in future $(80 \%$ in urban and $86 \%$ in rural site), with majority desiring spacing of four years or more (59\% in urban and $74 \%$ in rural site). Slightly more than half of the young mothers desired having between three and four children $(58 \%$ in urban and $52 \%$ in rural site) while most had one living child at the time of the survey (65\% in urban and $71 \%$ in rural site).

\begin{tabular}{|c|c|c|c|}
\hline Indicator & $\begin{array}{r}\text { Urban } \\
(\%)\end{array}$ & $\begin{array}{r}\text { Rural } \\
(\%)\end{array}$ & $\begin{array}{r}\text { Both sites } \\
(\%)\end{array}$ \\
\hline Number of times pregnant & $(\mathrm{N}=330)$ & $(\mathrm{N}=472)$ & $(\mathrm{N}=802)$ \\
\hline 1 & 87.3 & 91.5 & 89.8 \\
\hline 2 & 12.1 & 7.8 & 9.6 \\
\hline 3 & 0.3 & 0.6 & 0.5 \\
\hline 4 & 0.3 & 0.0 & 0.1 \\
\hline Age at first pregnancy (years) & $(\mathrm{N}=330)$ & $(\mathrm{N}=472)$ & $(\mathrm{N}=802)$ \\
\hline $11-14$ & 12.4 & 5.7 & 8.5 \\
\hline 15-17 & 58.2 & 67.2 & 63.5 \\
\hline $18-19$ & 28.5 & 26.1 & 27.1 \\
\hline Don't remember & 0.9 & 0.9 & 0.9 \\
\hline No answer & 0.0 & 0.2 & 0.1 \\
\hline Respondent intends to have more children & $(\mathrm{N}=330)$ & $(\mathrm{N}=472)$ & $(\mathrm{N}=802)$ \\
\hline No & 11.2 & 4.7 & 7.4 \\
\hline Yes & 80.3 & 86.0 & 83.7 \\
\hline Not sure/don't know & 7.9 & 8.7 & 8.4 \\
\hline No answer & 0.6 & 0.6 & 0.6 \\
\hline Preferred timing of next birth & $(\mathrm{N}=265)$ & $(\mathrm{N}=406)$ & $(\mathrm{N}=671)$ \\
\hline 1 year/within 1 year & 8.3 & 5.9 & 6.9 \\
\hline Between 2-3 years & 14.0 & 6.2 & 9.2 \\
\hline Between 4-5 years & 32.8 & 28.3 & 30.1 \\
\hline 6 years or more & 26.0 & 45.8 & 38.0 \\
\hline Not decided & 7.2 & 3.2 & 4.8 \\
\hline Don't know/up to God & 11.3 & 10.1 & 10.6 \\
\hline No answer & 0.4 & 0.5 & 0.5 \\
\hline Desired number of children & $(\mathrm{N}=330)$ & $(\mathrm{N}=472)$ & $(\mathrm{N}=802)$ \\
\hline $0-2$ & 16.4 & 19.5 & 18.2 \\
\hline $3-4$ & 57.6 & 51.5 & 54.0 \\
\hline 5 or more & 12.1 & 7.0 & 9.1 \\
\hline Don't know/up to God & 13.0 & 19.9 & 17.1 \\
\hline No answer & 0.9 & 2.1 & 1.6 \\
\hline Number of living children & $(\mathrm{N}=330)$ & $(\mathrm{N}=472)$ & $(\mathrm{N}=802)$ \\
\hline 0 & 27.9 & 15.7 & 20.7 \\
\hline 1 & 64.6 & 71.4 & 68.6 \\
\hline 2 & 4.9 & 1.9 & 3.1 \\
\hline 3 & 0.6 & 0.4 & 0.5 \\
\hline No answer & 2.1 & 10.6 & 7.1 \\
\hline
\end{tabular}




\section{Access to Reproductive Health Information}

The most common pieces of information on sexuality and reproductive health that young mothers had received were on pregnancy prevention (78\% in urban and $85 \%$ in rural site) and prevention of HIV/STIs (82\% in urban and $70 \%$ in rural site; Table 5). Less than half of young mothers in the rural site had obtained information on dating and relationships (46\%), menstrual cycle (43\%), having or not having children (43\%), responsible sexual behavior (31\%), and care for survivors of physical or sexual abuse (23\%). In contrast, a higher proportion of young mothers in the urban site had obtained information on these aspects $(61 \%, 66 \%$, $59 \%, 52 \%$, and $32 \%$ for dating and relationships, menstrual cycle, having or not having children, responsible sexual behavior, and care for survivors of physical or sexual violence respectively). The most common source of information on the issues was healthcare providers/counsellors (62\% in urban and 55\% in rural site), followed by friends or peers (52\% in urban and 33\% in rural site), teachers or guest speakers at school (42\% in urban and $21 \%$ in rural site), electronic media (30\% in urban and $13 \%$ in rural site), and parents/guardians ( $21 \%$ in urban and $14 \%$ in rural site) or other family members/relatives (10\% in urban and $15 \%$ in rural site).

Most (70\%) of the young mothers in the urban site and less than half (47\%) of those in the rural site were not satisfied with information on sexuality and reproductive health that they obtained from the mentioned sources (Table 5) although the majority were of the opinion that such information is appropriate for young girls of their age (95\% in urban and $85 \%$ in rural site). The most preferred sources of such information among young mothers in the urban site were healthcare providers or facilities (48\%), mass media including print, electronic or social media (21\%), and community gatekeepers including religious leaders and community health volunteers $(15 \%)$. Young mothers in the rural site mostly preferred to obtain such information from healthcare providers/facilities (44\%) or family members/relatives (20\%). Reasons for preference of specific sources included ease of access (58\% in urban and 33\% in rural site), credibility or reliability of information from such sources (41\% in urban and $58 \%$ in rural site), and confidentiality in the delivery of information (11\% in urban and $13 \%$ in rural site). In the opinions of the young mothers, the two most commonly mentioned strategies for preventing young girls from getting pregnant are provision of methods (45\% in urban and $71 \%$ in rural site) and provision of information on pregnancy prevention (59\% in urban and 33\% in rural site). Other mentioned actions included providing or supporting education for girls (34\% in urban and $10 \%$ in rural site) and promoting abstinence ( $22 \%$ in urban and $8 \%$ in rural site). 
TABLE 5: ACCESS TO REPRODUCTIVE HEALTH INFORMATION

\begin{tabular}{|c|c|c|c|}
\hline Indicator & $\begin{array}{r}\text { Urban } \\
(\%)\end{array}$ & $\begin{array}{r}\text { Rural } \\
(\%)\end{array}$ & $\begin{array}{r}\text { Both sites } \\
\text { (\%) }\end{array}$ \\
\hline Respondent ever obtained information on & $(\mathrm{N}=330)$ & $(\mathrm{N}=472)$ & $(\mathrm{N}=802)$ \\
\hline Menstrual cycle & 65.8 & 43.2 & 52.5 \\
\hline Dating and relationships & 60.9 & 46.2 & 52.2 \\
\hline Pregnancy prevention & 77.9 & 85.0 & 82.0 \\
\hline Prevention of HIV/STIS & 82.1 & 70.1 & 75.1 \\
\hline Having or not having children & 59.1 & 42.8 & 49.5 \\
\hline Responsible sexual behavior & 52.1 & 31.4 & 39.9 \\
\hline Care of survivors of physical or sexual violence & 32.4 & 22.7 & 26.7 \\
\hline Sources of informationa & $(\mathrm{N}=301)$ & $(\mathrm{N}=425)$ & $(\mathrm{N}=726)$ \\
\hline Parent/guardian & 20.6 & 13.7 & 16.5 \\
\hline Other family members/relatives & 10.0 & 14.8 & 12.8 \\
\hline At school from teachers/guest speakers & 41.9 & 20.9 & 29.6 \\
\hline Healthcare providers/counselors & 62.1 & 54.6 & 57.7 \\
\hline Community health workers & 10.6 & 7.5 & 8.8 \\
\hline Religious/traditional/political leaders & 2.0 & 1.4 & 1.7 \\
\hline Outreach/mobile clinics/road shows & 7.6 & 2.4 & 4.6 \\
\hline Friends/peers/fellow students & 51.5 & 32.9 & 40.6 \\
\hline Print media (newspapers/magazines) & 8.6 & 3.1 & 5.4 \\
\hline Electronic media (radio/TV/internet/SMS) & 29.9 & 12.5 & 19.7 \\
\hline Social media (Facebook/twitter) & 6.3 & 0.5 & 2.9 \\
\hline Other & 0.0 & 0.9 & 0.6 \\
\hline Satisfied with information obtained from the sources & $(\mathrm{N}=301)$ & $(\mathrm{N}=425)$ & $(\mathrm{N}=726)$ \\
\hline Yes & 28.6 & 50.1 & 41.2 \\
\hline No & 70.1 & 46.6 & 56.3 \\
\hline Don't know/not sure & 1.0 & 2.6 & 1.9 \\
\hline No answer & 0.3 & 0.7 & 0.6 \\
\hline Information is appropriate for young girls & $(\mathrm{N}=330)$ & $(\mathrm{N}=472)$ & $(\mathrm{N}=802)$ \\
\hline No & 3.6 & 6.1 & 5.1 \\
\hline Yes & 94.9 & 85.4 & 89.3 \\
\hline Don't know/not sure & 1.2 & 7.8 & 5.1 \\
\hline No answer & 0.3 & 0.6 & 0.5 \\
\hline Most preferred source of information & $(\mathrm{N}=329)$ & $(\mathrm{N}=469)$ & $(\mathrm{N}=798)$ \\
\hline Family members/relatives & 5.5 & 20.3 & 14.2 \\
\hline Healthcare providers/facility & 47.7 & 44.1 & 45.6 \\
\hline Community gatekeepers & 14.9 & 5.1 & 9.2 \\
\hline Mass media (print/electronic/social) & 21.0 & 6.8 & 12.7 \\
\hline Friends/peers & 2.1 & 8.3 & 5.8 \\
\hline Outreach/mobile clinics/road shows & 6.1 & 1.3 & 3.3 \\
\hline Other & 1.2 & 1.3 & 1.3 \\
\hline No answer & 1.5 & 12.8 & 8.2 \\
\hline Reasons for preference of source & $(\mathrm{N}=324)$ & $(\mathrm{N}=409)$ & $(\mathrm{N}=733)$ \\
\hline Ease of access & 58.3 & 33.0 & 44.2 \\
\hline Appealing/entertaining & 16.4 & 6.1 & 10.6 \\
\hline Confidentiality reasons & 10.5 & 13.0 & 11.9 \\
\hline Credibility/reliability & 41.4 & 58.0 & 50.6 \\
\hline Other & 9.6 & 5.1 & 7.1 \\
\hline Actions to prevent girls from getting pregnant & $(\mathrm{N}=330)$ & $(\mathrm{N}=472)$ & $(\mathrm{N}=802)$ \\
\hline Provide information on pregnancy prevention & 59.4 & 32.6 & 43.6 \\
\hline Provide methods for preventing pregnancy & 45.2 & 71.4 & 60.6 \\
\hline Provide/support their education & 33.9 & 10.2 & 20.0 \\
\hline Provide economic opportunities & 17.9 & 0.9 & 7.9 \\
\hline Punish those who make them pregnant & 7.9 & 4.0 & 5.6 \\
\hline Promote abstinence & 22.1 & 7.8 & 13.7 \\
\hline Don't know & 14.6 & 7.6 & 10.5 \\
\hline Other & 3.0 & 5.1 & 4.2 \\
\hline
\end{tabular}




\section{Circumstances of Pregnancy}

The young mothers reported a total of 890 pregnancies, with 90 percent being first order pregnancies while the rest were second, third, or fourth order pregnancies (not shown). Majority of the pregnancies occurred when respondents were aged between 15 and 17 years (57\% in urban and 65\% in rural site; Table 6). About half $(47 \%)$ of the pregnancies to young mothers in the urban site occurred when they were unemployed or were housewives while 72 percent of pregnancies to young mothers in the rural site occurred when they were engaged in domestic or farm work. Pregnancies to young mothers in the urban site occurred when they were living with relatives $(29 \%)$, single biological parents $(24 \%)$, both biological parents $(22 \%)$ or husband/partner/boyfriend (22\%). In contrast, majority (60\%) of pregnancies to young mothers in the rural site occurred when they were living with husband/partner/boyfriend. Among pregnancies to young mothers in the urban site, more than half (54\%) occurred when respondents were living with self-employed household breadwinners. In the rural site, 65 percent of the pregnancies occurred when respondents were living with household breadwinners who were engaged in domestic farm work.

More than three-quarters (79\%) of the pregnancies in the urban site and 46 percent of those in the rural site were unintended (Table 6). The major reason for not using a method to prevent unintended pregnancies in the urban site was lack of knowledge of methods or where to get them (43\%), followed by fear of side-effects $(19 \%)$, and respondents not thinking that they would get pregnant (17\%). The major reason for non-use of a method to prevent unintended pregnancies in the rural site was lack of knowledge of methods or where to get them (25\%), followed by method failure or incorrect use (23\%), fear of side-effects (15\%), respondents not thinking that they would get pregnant (14\%), and other reasons (12\%) including being denied a method at facility ( 7 cases), fear of going to facility or using a method ( 3 cases), forgetting to use a method ( 3 cases), and services being too far ( 3 cases). Steady boyfriends or fiancés were responsible for 51 percent of the pregnancies in the urban site while husbands or live-in partners were responsible 56 percent of the pregnancies in the rural site.

\section{Outcomes of Pregnancy}

About two-thirds of pregnancies in either site resulted in full-term term live birth (66\% in urban and $69 \%$ in rural site), with four percent of pregnancies in the urban site and five percent of those in the rural site resulting in pre-term live birth (Table 7). The proportion of pregnancies that resulted in wastage (miscarriage, stillbirth or abortion) was nearly twice as high in the urban as in the rural site (17\% and $10 \%$ respectively). Eleven percent of pregnancies in either site resulted in Caesarean section while the majority were normal deliveries ( $87 \%$ in urban and $89 \%$ in rural site). Nineteen percent of pregnancies in the urban site and 16 percent of those in the rural site resulted in complications, with the common types of complications being bleeding ( $35 \%$ in urban and $42 \%$ in rural site), convulsions (10\% in urban and $13 \%$ in rural site), problems walking ( $8 \%$ in urban and $9 \%$ in rural site), and other forms (45\% in urban and $31 \%$ in rural site) including stomach pains (22 cases), less blood or water in the body ( 6 cases), and prolonged healing of Caesarean scar ( 5 cases). Only six percent of babies who were born alive had died by the time of the survey in either site. 
TABLE 6: CIRCUMSTANCES OF PREGNANCY

\begin{tabular}{|c|c|c|c|}
\hline Indicator & $\begin{array}{r}\text { Urban } \\
(\%) \\
\end{array}$ & $\begin{array}{r}\text { Rural } \\
(\%) \\
\end{array}$ & $\begin{array}{r}\text { Both sites } \\
(\%) \\
\end{array}$ \\
\hline Age at pregnancy (years) & $(N=375)$ & $(N=515)$ & $(\mathrm{N}=890)$ \\
\hline $11-14$ & 11.5 & 5.2 & 7.9 \\
\hline $15-17$ & 56.5 & 64.9 & 61.4 \\
\hline $18-19$ & 30.9 & 28.9 & 29.8 \\
\hline Don't remember & 1.1 & 0.8 & 0.9 \\
\hline No answer & 0.0 & 0.2 & 0.1 \\
\hline Respondent's main occupation at time of pregnancy & $(\mathrm{N}=375)$ & $(\mathrm{N}=515)$ & $(\mathrm{N}=890)$ \\
\hline Student/attending school & 13.6 & 2.5 & 7.2 \\
\hline Unemployed/housewife & 46.9 & 15.7 & 28.9 \\
\hline Employed formal/informal & 8.5 & 3.3 & 5.5 \\
\hline Self-employed formal/informal & 15.7 & 4.9 & 9.4 \\
\hline Domestic/farm work & 9.1 & 72.2 & 45.6 \\
\hline Casual/part-time work & 6.1 & 0.8 & 3.0 \\
\hline Other & 0.0 & 0.6 & 0.3 \\
\hline Living arrangements at time of pregnancy & $(\mathrm{N}=375)$ & $(\mathrm{N}=515)$ & $(\mathrm{N}=890)$ \\
\hline Both biological parents & 22.4 & 11.7 & 16.2 \\
\hline Single biological parents & 24.0 & 12.8 & 17.5 \\
\hline Husband/partner/boyfriend & 21.9 & 60.2 & 44.0 \\
\hline Relatives & 29.1 & 12.2 & 19.3 \\
\hline Non-relatives/neighbor/alone & 2.7 & 2.9 & 2.8 \\
\hline Other & 0.0 & 0.2 & 0.1 \\
\hline Main occupation of breadwinner at time of pregnancy & $(\mathrm{N}=369)$ & $(\mathrm{N}=512)$ & $(\mathrm{N}=881)$ \\
\hline Unemployed & 13.8 & 3.7 & 8.0 \\
\hline Employed formal/informal & 15.5 & 11.5 & 13.2 \\
\hline Self-employed formal/informal & 54.2 & 16.2 & 32.1 \\
\hline Domestic/farm work & 10.6 & 65.0 & 42.2 \\
\hline Casual/part-time & 5.7 & 2.9 & 4.1 \\
\hline Other & 0.3 & 0.4 & 0.3 \\
\hline No answer & 0.0 & 0.2 & 0.1 \\
\hline Respondent intended to become pregnant then & $(\mathrm{N}=375)$ & $(\mathrm{N}=515)$ & $(\mathrm{N}=890)$ \\
\hline No & 78.7 & 45.6 & 59.6 \\
\hline Yes & 21.1 & 54.2 & 40.2 \\
\hline No answer & 0.3 & 0.2 & 0.2 \\
\hline Main reason for not using a method to prevent pregnancy & $(\mathrm{N}=295)$ & $(\mathrm{N}=235)$ & $(\mathrm{N}=530)$ \\
\hline Partner refusal & 6.4 & 9.4 & 7.7 \\
\hline Lack of knowledge & 43.4 & 25.1 & 35.3 \\
\hline Worried about side-effects & 19.3 & 14.5 & 17.2 \\
\hline Didn't think would get pregnant & 17.0 & 14.0 & 15.7 \\
\hline Method failure/incorrect use & 9.2 & 23.0 & 15.3 \\
\hline Other & 3.1 & 11.5 & 6.8 \\
\hline No answer & 1.7 & 2.6 & 2.1 \\
\hline Relationship to person responsible for pregnancy & $(\mathrm{N}=375)$ & $(\mathrm{N}=515)$ & $(\mathrm{N}=890)$ \\
\hline Steady boyfriend/fiancé & 51.2 & 26.6 & 37.0 \\
\hline Husband/live-in partner & 21.9 & 56.3 & 41.8 \\
\hline Friend/acquaintance & 25.3 & 15.9 & 19.9 \\
\hline Other & 0.8 & 0.4 & 0.6 \\
\hline No answer & 0.8 & 0.8 & 0.8 \\
\hline
\end{tabular}




\section{TABLE 7: OUTCOMES OF PREGNANCY}

\begin{tabular}{|c|c|c|c|}
\hline Indicator & $\begin{array}{r}\text { Urban } \\
(\%)\end{array}$ & $\begin{array}{r}\text { Rural } \\
(\%)\end{array}$ & $\begin{array}{r}\text { Both sites } \\
(\%)\end{array}$ \\
\hline Outcome of pregnancy & $(N=375)$ & $(N=515)$ & $(\mathrm{N}=890)$ \\
\hline Full-term live birth & 65.6 & 68.5 & 67.3 \\
\hline Pre-term live birth & 3.7 & 4.9 & 4.4 \\
\hline Miscarriage/stillbirth & 12.8 & 9.1 & 10.7 \\
\hline Ended it/abortion & 4.3 & 0.6 & 2.1 \\
\hline Still pregnant & 13.1 & 16.7 & 15.2 \\
\hline No answer & 0.5 & 0.2 & 0.3 \\
\hline Type of deliverya & $(\mathrm{N}=241)$ & $(\mathrm{N}=370)$ & $(\mathrm{N}=611)$ \\
\hline Normal vaginal & 86.7 & 89.2 & 88.2 \\
\hline Assisted vaginal & 2.5 & 0.3 & 1.2 \\
\hline Caesarean section & 10.8 & 10.5 & 10.6 \\
\hline $\begin{array}{l}\text { Respondent experienced complications after } \\
\text { delivery/pregnancy termination }\end{array}$ & $(\mathrm{N}=325)$ & $(N=428)$ & $(N=753)$ \\
\hline No & 81.5 & 83.9 & 82.9 \\
\hline Yes & 18.5 & 15.7 & 16.9 \\
\hline No answer & 0.0 & 0.5 & 0.3 \\
\hline Type of complications experienced ${ }^{b}$ & $(\mathrm{~N}=60)$ & $(\mathrm{N}=67)$ & $(\mathrm{N}=128)$ \\
\hline Bleeding & 35.0 & 41.8 & 38.6 \\
\hline Unable to hold urine & 0.0 & 1.5 & 0.8 \\
\hline Convulsions/fitting/seizure & 10.0 & 13.4 & 11.8 \\
\hline Sepsis/infection & 1.7 & 0.0 & 0.8 \\
\hline Problems walking & 8.3 & 9.0 & 8.7 \\
\hline Other & 45.0 & 31.3 & 37.8 \\
\hline No answer & 0.0 & 3.0 & 1.6 \\
\hline Baby is still alive & $(\mathrm{N}=258)$ & $(\mathrm{N}=375)$ & $(\mathrm{N}=633)$ \\
\hline No & 6.2 & 5.6 & 5.9 \\
\hline Yes & 93.8 & 94.4 & 94.2 \\
\hline
\end{tabular}

Findings from in-depth interviews with young mothers showed that poor pregnancy outcomes such as abortion, miscarriage or stillbirth were due to various factors related to the individual, the family and health facility. Individual-level factors included pre-existing health conditions (such HIV infection, STIs, and high blood pressure), psychological stress associated with unintended pregnancy, and no or late initiation of clinic visits because of feelings of embarrassment, especially in cases of sexual assault, being tricked into sexual intercourse, and pregnancies occurring at a very early age. Although availability of ART should ideally reduce the chances of poor pregnancy outcomes resulting HIV infection, interviews with young mothers who were infected showed that non-disclosure of status to the child and late initiation of treatment increase such risk. Family-level factors included being disowned by parents or partner, delayed decision-making at the household level to seek care due to lack of resources or influence of grandparents, intimate partner violence, or suspicion of foul play in cases of extended families. At the facility level, young mothers mentioned lack of relevant services or supplies, long distance to alternative facilities, poor means of transport (use of motorcycles), poor treatment by providers (especially female nurses), and not being provided with appropriate care as some of the reasons why they experienced poor pregnancy outcomes.

I was born with HIV... and I didn't know that I have HIV... I went to check for HIV when I got a sexual partner. When I got the results, I disclosed them to my family. That's when they told me that I was born with it... so I started using ARTs [antiretroviral treatment]... I delivered safely, the drip was still running... after delivering the baby cried once, they wrapped it nicely so I could see it...but when they checked the baby later, they realized it was dead, but because I was young they didn't tell me. They waited when adults came and they told them...I don't think they told them anything about the cause of death.

(Young mother, 15-19 years, urban site)

He would leave here and go to women...and would want me to stay at home and find me in the morning. Because I loved him, I obeyed. And whenever I asked him where he went, he never liked being asked such questions, he would beat me so badly. 
When in the village, my first pregnancy was not felt until when I had to be taken on a long motorcycle ride to hospital and was given some medicine...the dose was very strong and I got a miscarriage thereafter.

(Young mother, 15-19 years, rural site)

\section{Access to Healthcare Services}

Young mothers in either site sought antenatal care for most of the pregnancies $(84 \%$ in urban and $93 \%$ in rural site; Table 8). For pregnancies for which mothers did not seek antenatal care, the most common reasons were lack of knowledge about it or where to go (18\% in urban and $27 \%$ in rural site), feeling of embarrassment (15\% in urban and 3\% in rural site), lack of money or partner refusal ( $7 \%$ in urban and $9 \%$ in rural site), and other reasons (50\% in urban and $59 \%$ in rural site) including feeling that it was not yet time to start attending clinic (21 cases), planned to carry out abortion, aborted or had miscarriage (12 cases), and that the pregnancy ended before they could start attending clinic (6 cases). Mothers made four or more antenatal care visits for more than half $(60 \%)$ of the pregnancies in the urban site and less than half $(48 \%)$ of the pregnancies in the rural site.

Mothers received PMTCT services for about one-third (34\%) of the pregnancies in the urban site and about half $(52 \%)$ of the pregnancies in the rural site, with the majority making less than three visits ( $57 \%$ in urban and $69 \%$ in rural site; Table 8 ). For pregnancies for which mothers did not receive PMTCT services, the most commonly mentioned reason was that they were HIV-negative ( $70 \%$ in urban and $71 \%$ in rural site), followed by lack of knowledge about it or where to go (14\% in urban and $8 \%$ in rural site). Other reasons ( $8 \%$ in urban and $16 \%$ in rural site) were that the respondents had not started attending clinic (21 cases), they did not know about their HIV status (7 cases), or the facility lacked equipment or services (4 cases).

Most deliveries in either site occurred in a health facility ( $86 \%$ in urban and $85 \%$ in rural site) under a skilled provider i.e. doctor, nurse or midwife ( $86 \%$ in urban and $85 \%$ in rural site; Table 8 ). The most common reasons for deliveries that did not take place in a facility were lack of knowledge about it or where to go (16\% in urban and $13 \%$ in rural site), lack of money or partner refusal (13\% in urban and $10 \%$ in rural site), facility being too far ( $4 \%$ in urban and $31 \%$ in rural site), and other reasons (33\% in urban and $38 \%$ in rural site) including abrupt labor or labor occurring at night (13 cases), miscarriage or the pregnancy ending early ( 7 cases), and fear of going to the facility ( 4 cases).

Mothers sought care at a facility for about two-thirds (62\%) of delivery-related complications that occurred in the urban site and 85 percent of those in the rural site (Table 9). The reasons for not seeking care for complications at a health facility included lack of money ( $27 \%$ in urban and $22 \%$ in rural site), perception that the condition was not serious ( $23 \%$ in urban and $11 \%$ in rural site), lack of knowledge about it or where to go (5\% in urban and $56 \%$ in rural site), and other reasons ( $27 \%$ in urban an $11 \%$ in rural site) such as using herbal medicine ( 3 cases) and obtaining services from a pharmacy ( 2 cases). Mothers sought health check-up after delivery or pregnancy termination for more than half $(57 \%)$ of the pregnancies in the urban site and less than half $(46 \%)$ of the pregnancies in the rural site. Reasons for not seeking health check-up after delivery or pregnancy termination included lack of knowledge about it or where to go (57\% in urban and $62 \%$ in rural site), lack of money ( $11 \%$ in urban and $4 \%$ in rural site), and other reasons ( $23 \%$ in urban and $18 \%$ in rural site) such as feeling that there was no health problem hence no need (55 cases), planning to go after a certain period of time following delivery or pregnancy termination ( 7 cases), and being told to go in case of complications ( 3 cases). 
TABLE 8: ACCESS TO ANTENATAL AND DELIVERY CARE SERVICES

\begin{tabular}{|c|c|c|c|}
\hline Indicator & $\begin{array}{r}\text { Urban } \\
(\%)\end{array}$ & $\begin{array}{r}\text { Rural } \\
(\%)\end{array}$ & $\begin{array}{r}\text { Both sites } \\
\text { (\%) }\end{array}$ \\
\hline Respondent sought antenatal care during pregnancy & $(N=375)$ & $(N=515)$ & $(\mathrm{N}=890)$ \\
\hline No & 16.0 & 6.6 & 10.6 \\
\hline Yes & 84.0 & 93.4 & 89.4 \\
\hline Main reason for not seeking antenatal care & $(\mathrm{N}=60)$ & $(\mathrm{N}=34)$ & $(\mathrm{N}=94)$ \\
\hline Lack of knowledge & 18.3 & 26.5 & 21.3 \\
\hline Lack of money/partner refusal & 6.7 & 8.8 & 7.5 \\
\hline Unfriendly providers & 3.3 & 0.0 & 2.1 \\
\hline Feeling of embarrassment & 15.0 & 2.9 & 10.6 \\
\hline Other & 50.0 & 58.8 & 53.2 \\
\hline No answer & 6.7 & 2.9 & 5.3 \\
\hline Respondent made four or more antenatal care visits & $(\mathrm{N}=315)$ & $(\mathrm{N}=481)$ & $(\mathrm{N}=796)$ \\
\hline No & 34.9 & 40.8 & 38.4 \\
\hline Yes & 59.7 & 48.4 & 52.9 \\
\hline Don't remember & 5.4 & 10.8 & 8.7 \\
\hline Respondent received PMTCT services & $(\mathrm{N}=375)$ & $(\mathrm{N}=515)$ & $(\mathrm{N}=890)$ \\
\hline No & 59.7 & 46.0 & 51.8 \\
\hline Yes & 34.9 & 51.7 & 44.6 \\
\hline No answer & 5.3 & 2.3 & 3.6 \\
\hline Main reason for not receiving PMTCT services & $(\mathrm{N}=224)$ & $(\mathrm{N}=237)$ & $(\mathrm{N}=461)$ \\
\hline Lack of knowledge & 14.3 & 8.4 & 11.3 \\
\hline Lack of money & 0.0 & 1.7 & 0.9 \\
\hline Facility too far & 0.0 & 0.8 & 0.4 \\
\hline Feeling of embarrassment & 1.8 & 0.0 & 0.9 \\
\hline Respondent is HIV-negative & 70.1 & 70.9 & 70.5 \\
\hline Other & 8.0 & 15.6 & 11.9 \\
\hline No answer & 5.8 & 2.5 & 4.1 \\
\hline Number of PMTCT visits & $(\mathrm{N}=131)$ & $(\mathrm{N}=266)$ & $(\mathrm{N}=397)$ \\
\hline 1 & 29.8 & 36.8 & 34.5 \\
\hline 2 & 27.5 & 32.0 & 30.5 \\
\hline 3 or more & 31.1 & 21.1 & 24.4 \\
\hline Don't remember & 9.2 & 4.5 & 6.1 \\
\hline No answer & 2.3 & 5.6 & 4.5 \\
\hline Place of delivery/pregnancy termination & $(\mathrm{N}=325)$ & $(\mathrm{N}=428)$ & $(\mathrm{N}=753)$ \\
\hline Health facility & 85.5 & 84.6 & 85.0 \\
\hline On transit to facility & 0.6 & 1.2 & 0.9 \\
\hline Home & 10.8 & 13.3 & 12.2 \\
\hline Other & 1.2 & 0.2 & 0.7 \\
\hline No answer & 1.9 & 0.7 & 1.2 \\
\hline Main reason for not delivering/ending pregnancy at a facility & $(\mathrm{N}=45)$ & $(\mathrm{N}=61)$ & $(\mathrm{N}=106)$ \\
\hline Lack of knowledge & 15.6 & 13.1 & 14.2 \\
\hline Lack of money/partner refusal & 13.3 & 9.8 & 11.3 \\
\hline Facility too far & 4.4 & 31.2 & 19.8 \\
\hline Unfriendly providers & 2.2 & 1.6 & 1.9 \\
\hline Feeling of embarrassment & 6.7 & 0.0 & 2.8 \\
\hline Other & 33.3 & 37.7 & 35.9 \\
\hline No answer & 24.4 & 6.6 & 14.2 \\
\hline Person who assisted during delivery/pregnancy termination & $(\mathrm{N}=324)$ & $(\mathrm{N}=428)$ & $(\mathrm{N}=752)$ \\
\hline Doctor/nurse/midwife & 86.4 & 85.1 & 85.6 \\
\hline CHW/TBA & 0.3 & 1.9 & 1.2 \\
\hline Relative & 6.2 & 9.6 & 8.1 \\
\hline No one & 2.2 & 1.6 & 1.9 \\
\hline Other & 3.1 & 0.9 & 1.9 \\
\hline No answer & 1.9 & 0.9 & 1.3 \\
\hline
\end{tabular}


Mothers used family planning after delivery or pregnancy termination for less than half $(41 \%)$ of the pregnancies in the urban site and more than half (58\%) of those in the rural site). The methods commonly used in the urban site were injectables (52\%), implants (29\%), emergency pills (18\%), and calendar method (16\%) while in the rural site, the most commonly used methods were injectables (55\%), implants (43\%), and calendar method (10\%; Figure 3). The most common reasons for not using a method after delivery or pregnancy termination were fear of side-effects (33\% in urban and $7 \%$ in rural site), lack of knowledge about methods (16\% in urban and $10 \%$ in rural site), and other reasons (38\% in urban and $48 \%$ in rural site; Figure 4 ) including being told to go for a method after a certain period of time following delivery (91 cases), not having or not planning to have sex (40 cases), dislike for family planning methods (6 cases), and indecision regarding whether to use or not seeing the need (5 cases).

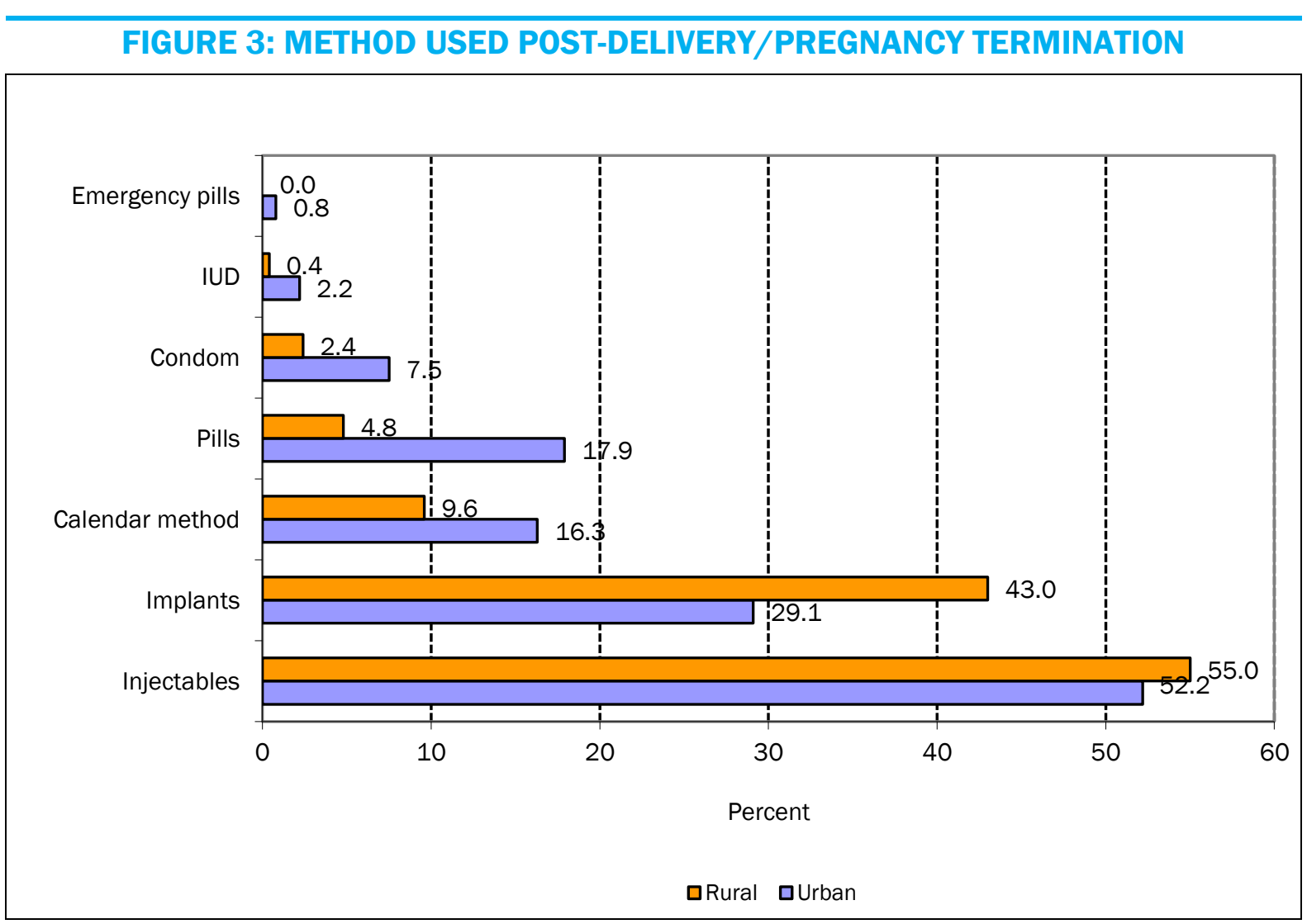


FIGURE 4: REASONS FOR NON-USE OF A METHOD AFTER DELIVERY/PREGNANCY TERMINATION

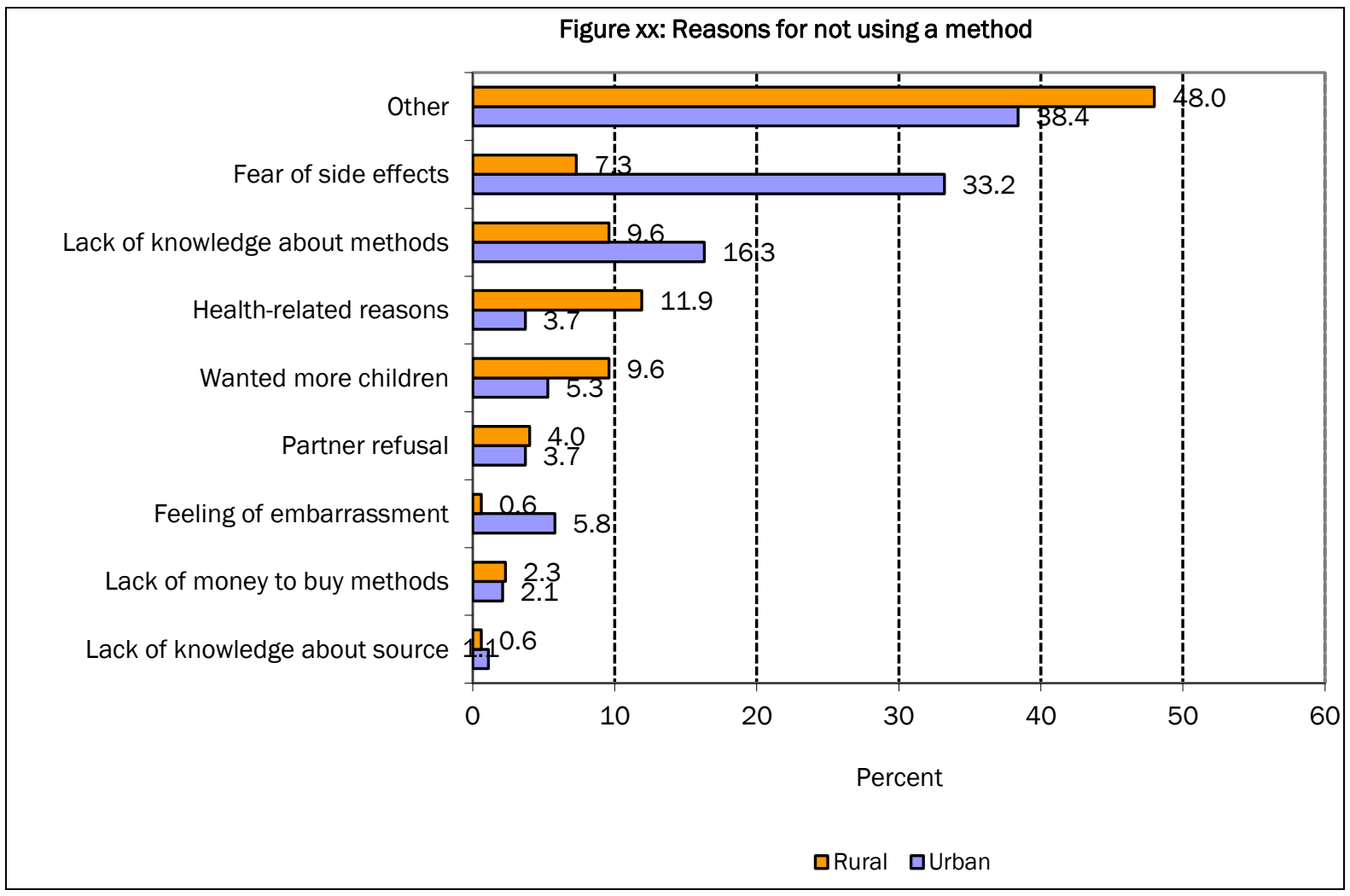

Mothers sought health check-up from a healthcare provider for most of the babies who were born alive (93\% in urban and $82 \%$ in rural site; Table 9). Reasons for not seeking health check-up for babies included lack of knowledge about it (35\% in urban and $58 \%$ in rural site, baby dying after birth (29\% in urban and $14 \%$ in rural site), and other reasons ( $24 \%$ in urban and $20 \%$ in rural site) such as the feeling that it was still too early (12 cases) or that the baby did not have any problem ( 3 cases). Less than half of the babies in either site were tested for HIV (45\% in urban and $38 \%$ in rural site) while respondents were willing to share test results for nearly all babies who tested ( $97 \%$ in urban and $98 \%$ in rural site). Three percent of babies in the urban site and one percent of those in the rural site whose mothers shared test results were HIV-positive. 
TABLE 9: ACCESS TO POSTNATAL AND HIV CARE SERVICES

\begin{tabular}{|c|c|c|c|}
\hline Indicator & $\begin{array}{r}\text { Urban } \\
(\%)\end{array}$ & $\begin{array}{r}\text { Rural } \\
(\%)\end{array}$ & $\begin{array}{r}\text { Both sites } \\
(\%)\end{array}$ \\
\hline Respondent sought care at facility for complications & $(\mathrm{N}=61)$ & $(\mathrm{N}=67)$ & $(\mathrm{N}=128)$ \\
\hline No & 36.1 & 13.4 & 24.2 \\
\hline Yes & 62.3 & 85.1 & 74.2 \\
\hline No answer & 1.6 & 1.5 & 1.6 \\
\hline Main reason for not seeking care at facility & $(\mathrm{N}=22)$ & $(\mathrm{N}=9)$ & $(\mathrm{N}=31)$ \\
\hline Lack of knowledge & 4.6 & 55.6 & 19.4 \\
\hline Lack of money & 27.3 & 22.2 & 25.8 \\
\hline Facility too far & 4.6 & 0.0 & 3.2 \\
\hline Feeling of embarrassment & 4.6 & 0.0 & 3.2 \\
\hline Not serious condition & 22.7 & 11.1 & 19.4 \\
\hline Other & 27.3 & 11.1 & 22.6 \\
\hline No answer & 9.1 & 0.0 & 6.5 \\
\hline $\begin{array}{l}\text { Respondent sought health check-up from a facility after } \\
\text { delivery/pregnancy termination }\end{array}$ & $(\mathrm{N}=325)$ & $(\mathrm{N}=428)$ & $(\mathrm{N}=753)$ \\
\hline No & 43.4 & 53.5 & 49.1 \\
\hline Yes & 56.6 & 46.0 & 50.6 \\
\hline No answer & 0.0 & 0.5 & 0.3 \\
\hline Main reason for not seeking health check-up from a facility & $(\mathrm{N}=141)$ & $(\mathrm{N}=229)$ & $(\mathrm{N}=370)$ \\
\hline Lack of knowledge & 56.7 & 62.0 & 60.0 \\
\hline Lack of money & 11.4 & 3.9 & 6.8 \\
\hline Facility too far & 0.0 & 2.6 & 1.6 \\
\hline Unfriendly providers & 0.0 & 2.2 & 1.4 \\
\hline Feeling of embarrassment & 0.7 & 0.0 & 0.3 \\
\hline Husband/partner refusal & 0.7 & 0.9 & 0.8 \\
\hline Other & 22.7 & 18.3 & 20.0 \\
\hline No answer & 7.8 & 10.0 & 9.2 \\
\hline $\begin{array}{l}\text { Respondent used family planning after delivery/ pregnancy } \\
\text { termination }\end{array}$ & $(\mathrm{N}=325)$ & $(\mathrm{N}=428)$ & $(\mathrm{N}=753)$ \\
\hline No & 58.5 & 41.4 & 48.7 \\
\hline Yes & 41.2 & 58.2 & 50.9 \\
\hline No answer & 0.3 & 0.5 & 0.4 \\
\hline Respondent sought check-up for baby's health & $(\mathrm{N}=258)$ & $(\mathrm{N}=375)$ & $(\mathrm{N}=633)$ \\
\hline No & 6.6 & 17.6 & 13.1 \\
\hline Yes & 92.6 & 81.9 & 86.3 \\
\hline No answer & 0.8 & 0.5 & 0.6 \\
\hline Main reason for not seeking health check-up for baby & $(\mathrm{N}=17)$ & $(\mathrm{N}=66)$ & $(\mathrm{N}=83)$ \\
\hline Lack of knowledge about it & 35.3 & 57.6 & 53.0 \\
\hline Lack of money & 0.0 & 3.0 & 2.4 \\
\hline Facility too far & 0.0 & 1.5 & 1.2 \\
\hline Husband/partner refusal & 0.0 & 1.5 & 1.2 \\
\hline Baby died after birth & 29.4 & 13.6 & 16.9 \\
\hline Other & 23.5 & 19.7 & 20.5 \\
\hline No answer & 11.8 & 3.0 & 4.8 \\
\hline Baby tested for HIV & $(\mathrm{N}=258)$ & $(\mathrm{N}=375)$ & $(\mathrm{N}=633)$ \\
\hline No & 49.6 & 55.2 & 52.9 \\
\hline Yes & 44.6 & 37.6 & 40.4 \\
\hline No answer & 5.8 & 7.2 & 6.6 \\
\hline Respondent willing to share test results & $(\mathrm{N}=115)$ & $(\mathrm{N}=141)$ & $(\mathrm{N}=256)$ \\
\hline No & 0.9 & 1.4 & 1.2 \\
\hline Yes & 97.4 & 97.9 & 97.7 \\
\hline No answer & 1.7 & 0.7 & 1.2 \\
\hline Result of HIV test & $(\mathrm{N}=112)$ & $(\mathrm{N}=138)$ & $(\mathrm{N}=250)$ \\
\hline HIV-positive & 2.7 & 0.7 & 1.6 \\
\hline HIV-negative & 97.3 & 98.6 & 98.0 \\
\hline Could not be determined & 0.0 & 0.7 & 0.4 \\
\hline
\end{tabular}


In-depth interviews with young mothers who did not seek care from a health facility showed that some of the reasons included lack of information on available services, circumstances in which the pregnancy occurred (such as forced sex or very young age) which led to feeling of embarrassment, being disowned by parents or partner, poor socio-economic conditions, the requirement at the facility to be accompanied by a partner, abrupt or early occurrence of pregnancy wastage (abortion, miscarriage or stillbirth occurring too soon after conception), and perceived poor treatment by healthcare providers.

I was in class six. That boy was my classmate and he was seducing me but I kept saying no to him... One day he brought me juice... He told me he had brought me a gift. I accepted but I did not know he had drugged the juice... I drunk it and fell asleep... When I woke up, I found myself in the room that I had never been in...I did not want to go to hospital because I already knew what they had done to me... They [parents] insisted I should be taken to hospital but I refused and ran to my aunt's place. When she asked me why I was running I said someone was just chasing me... My mother came and I told her that I would rather commit suicide than go to hospital.

\section{(Young mother, 12-14 years, urban site)}

I saw blood coming out while I was pregnant...so I stayed at home and more blood was coming out with severe abdominal pain. So I went to the toilet and more blood kept coming out with things that I did not clearly understand. I was scared to go the hospital and I had no money to pay for the charges...so I thought that I would rather take some medications. I don't even know what they are called...I went and explained the condition to a lady at the pharmacy and she gave me the medications to clear out everything so I took the medications and blood kept coming out until the pregnancy was lost.

(Young mother, 15-19 years, urban site)

Ahh, it just happened as an accident. I wasn't aware about family planning. Even the adults didn't tell me that since I am grown up I should use this so as to protect myself from becoming pregnant, they didn't tell me that... After becoming pregnant, they took me and made me just to stay indoors. They were teaching me how to maintain it [the pregnancy] and when I delivered they were helping me. There came some of the elderly women who gave me instructions.

(Young mother, 15-19 years, rural site)

Besides inability to access care, some young mothers reported experiencing poor services when they sought care at a facility. These included long waiting time before being served, unfriendliness on the part of healthcare providers, lack of clear instructions from providers, being abandoned after delivery, lack of medication or supplies, improper diagnosis, being denied services until one came with her partner, and being asked to pay certain amount of money despite being told that services in government health facilities were free.

When approaching delivery, I was very ill...From the illness, I became very weak. I could not push the baby [during delivery] and when I told the nurse, unfortunately the nurse on duty that day was very cruel; she told me very bad words. I became very weak I could not push anymore. I asked them to operate on me. They gave intravenous drips and spoke very harshly to me while mocking me. The baby then came out spontaneously; they cleaned me up. The challenge I faced at the hospital was that I shared a bed with two other mothers before delivery. After delivery I went to the ward and shared a bed with another mother.

(Young mother, 15-19 years, urban site)

She talks a lot and she stops providing services. Her way of delivering services is different from the plans and if you go to the health center...that the service can be delayed. You can go in the morning and come back at this hour. You can go in the morning and come back at noon or one o'clock, and that is not good for a pregnant woman. (Young mother, 15-19 years, rural site)

I went there, they asked me if I can talk. I said yes. They asked me what I was suffering from...I told them it was my abdomen. They did not ask me to go for check-up...they prescribed a medication and told me to go and buy from outside; they did not have those medications. I went back home but still my abdomen was too painful. When my elders checked my abdomen, they said I was about to give birth because the abdomen sagged a little.

(Young mother, 15-19 years, rural site) 


\section{Consequences of Pregnancy}

The most common negative life changes during pregnancy for young mothers in the urban site were worsening of economic status (36\%), worsening of health status $(25 \%)$, and being mocked by family members, friends or neighbors (24\%; Table 10). Only a small fraction of the pregnancies to mothers in the urban site resulted in positive life changes such as improvements in health or economic status (5\% and $7 \%$ respectively) while no life changes occurred for 41 percent of the pregnancies. Young mothers in the rural site reported that there were no life changes for 70 percent of the pregnancies while notable negative changes were worsening of health and economic status (11\% and $8 \%$ respectively). Similar to urban site, only a small fraction of pregnancies in the rural site resulted in positive changes including improvements in economic or health status ( $5 \%$ and $3 \%$ respectively).

Worsening of economic and health status remained the most common negative life changes for young mothers in the urban site after delivery or pregnancy termination (35\% and $18 \%$ respectively) while being welcomed back home as well as improvements in health or economic status were some of the notable positive changes $(12 \%, 8 \%$ and $5 \%$ respectively; Table 10$)$. In the rural site, the most common negative life changes following delivery or pregnancy termination were worsening of economic or health status $(9 \%$ and $6 \%$ respectively) while notable positive changes were being welcomed back home and improvements in economic status ( $4 \%$ and $3 \%$ respectively). There were no life changes for less than half $(48 \%)$ and more than three-quarters $(79 \%)$ of pregnancies in urban rural sites respectively.

Consistent with findings from the quantitative interviews, in-depth interviews with young mothers showed that being disowned by family members or partner, loss of sense of worth, dropping out of school, psychological stress, and worsening socio-economic conditions were some of the consequences of getting pregnant at an early age.

It [the pregnancy] affected everything, actually I was very sad. First of all, it made me abandon my studies. Secondly, I lost my value. I got a lot of trouble. I became like a street child when I was chased away from home...It was very tough, I was thinking too much, I barely afforded my meals and yet I was pregnant. I lived a miserable life... I was in the streets selling groundnuts. They [community members] abused me but I was patient because I wanted to get some money for food.

(Young mother, 15-19 years, urban site)

I felt bad because I saw my fellow youths living with their parents while I was married living with a husband. It felt like am not being treated right... they come wearing their clothes, make fun of me.

(Young mother, 15-19 years, rural site) 


\section{TABLE 10: CONSEQUENCES OF PREGNANCY}

\begin{tabular}{|c|c|c|c|}
\hline Indicator & $\begin{array}{r}\text { Urban } \\
(\%)\end{array}$ & $\begin{array}{r}\text { Rural } \\
(\%)\end{array}$ & $\begin{array}{r}\text { Both sites } \\
(\%)\end{array}$ \\
\hline Life changes as a result of pregnancya & $(\mathrm{N}=375)$ & $(\mathrm{N}=515)$ & $(\mathrm{N}=890)$ \\
\hline Sent away from home & 8.0 & 1.6 & 4.3 \\
\hline Suspended/expelled from school & 5.1 & 1.0 & 2.7 \\
\hline Loss of employment & 4.5 & 0.8 & 2.4 \\
\hline Forced/decided to get married & 1.3 & 3.3 & 2.5 \\
\hline Mocked by family members/friends/neighbors & 23.5 & 4.3 & 12.4 \\
\hline Deserted by friends/partner & 12.0 & 5.8 & 8.4 \\
\hline Health changed for worse & 25.3 & 11.1 & 17.1 \\
\hline Health changed for better & 5.3 & 2.9 & 3.9 \\
\hline Economic status worsened & 36.3 & 8.2 & 20.0 \\
\hline Economic status improved & 6.9 & 4.5 & 5.5 \\
\hline No life changes & 40.5 & 69.9 & 57.5 \\
\hline Other & 4.8 & 3.9 & 4.3 \\
\hline Life changes after delivery/pregnancy terminationa & $(\mathrm{N}=325)$ & $(\mathrm{N}=428)$ & $(\mathrm{N}=753)$ \\
\hline Welcomed back home & 11.7 & 4.4 & 7.6 \\
\hline Returned to school & 0.6 & 0.0 & 0.3 \\
\hline Returned to employment & 0.6 & 0.0 & 0.3 \\
\hline Forced/decided to get married & 2.8 & 1.9 & 2.3 \\
\hline Mocked by family members/friends/neighbors & 6.5 & 1.2 & 3.5 \\
\hline Deserted by friends/partner & 4.6 & 2.6 & 3.5 \\
\hline Health changed for worse & 17.9 & 6.3 & 11.3 \\
\hline Health changed for better & 8.0 & 2.3 & 4.8 \\
\hline Economic status worsened & 34.8 & 8.6 & 19.9 \\
\hline Economic status improved & 4.6 & 2.6 & 3.5 \\
\hline No life changes & 48.0 & 78.7 & 65.5 \\
\hline Other & 4.3 & 1.6 & 2.8 \\
\hline
\end{tabular}

\section{Experiences of Intimate Partner Violence}

Intimate partner violence was measured by a total of 18 indicators capturing emotional, verbal, physical and sexual actions by partners of young mothers that were harmful to them during pregnancy. About two-thirds (65\%) of the young mothers reported experiencing at least one form of intimate partner violence during a pregnancy (63\% in urban and $67 \%$ in rural site; not shown). Mothers experienced intimate partner violence for 60 percent of the pregnancies in the urban and 66 percent of the pregnancies in the rural site (Table 11). The most common forms of intimate partner violence were insistence on knowing the respondent was at all times (32\% in urban and a similar proportion in rural site), jealousy or anger if the respondent talked to other men (32\% in urban and $26 \%$ in rural site), not trusting the respondent with any money ( $18 \%$ in urban and a similar proportion in rural site), frequently accusing the respondent of being unfaithful (20\% in urban and $16 \%$ in rural site), slapping the respondent (16\% in urban and $19 \%$ in rural site), insulting the respondent or making her feel bad about others (19\% in urban and $17 \%$ in rural site), not permitting the respondent to meet with female friends ( $16 \%$ in urban and a similar proportion in rural site), pushing, shaking or throwing something at the respondent (10\% in urban and $17 \%$ in rural site), physically forcing the respondent to have sexual intercourse when she did not want (11\% in urban and $14 \%$ in rural site), saying or doing something to humiliate the respondent in front of others (16\% in urban and $9 \%$ in rural site), punching the respondent ( $8 \%$ in urban and $12 \%$ in rural site), and threatening or hurting the respondent or someone close to her (10\% in urban and $11 \%$ in rural site). Some of these experiences also came up during in-depth interviews with young mothers.

I lacked care; you know, the care a pregnant woman deserves. I did not get it... Yes there was no peace, no one was around to advise me in anything...When he came home, he was furious all the time and he was abusive to me... In case I made a mistake at home, he lamented and told people he was helping me and he called me a whore... Finally he chased me away 
(Young mother, 15-19 years, urban site)

When I was told that I was pregnant, my husband accepted it and bought everything that was needed at the hospital. Then when the pregnancy was about five months, we started quarrelling. We fought as he started going out with other people outside; then I told him, 'What you are doing is not good.' I went and informed his relatives including his father who said he will call him, and he called him and held discussions and he said fine. Then it became worse, like I told him to worsen it. He started returning home at $10 \mathrm{pm}, 11 \mathrm{pm}$, even in the morning on some days, and when I asked where I would get help if I needed to go to the hospital at night, he said, “Aah! Don't ask me, just ask me whether you eat"...and in the end we separated. (Young mother, 15-19 years, rural site)

\begin{tabular}{|c|c|c|c|}
\hline Indicator & $\begin{array}{r}\text { Urban } \\
(\%)\end{array}$ & $\begin{array}{r}\text { Rural } \\
(\%)\end{array}$ & $\begin{array}{r}\text { Both sites } \\
(\%)\end{array}$ \\
\hline Aspects of intimate partner violence & $(N=375)$ & $(\mathrm{N}=515)$ & $(\mathrm{N}=890)$ \\
\hline Partner was jealous or angry if respondent talked to other men & 31.5 & 26.4 & 28.5 \\
\hline Partner frequently accused respondent of being unfaithful & 19.7 & 16.3 & 17.8 \\
\hline Partner did not permit respondent to meet female friends & 15.5 & 16.1 & 15.8 \\
\hline Partner tried to limit respondent's contact with her family & 2.7 & 6.8 & 5.1 \\
\hline Partner insisted on knowing where respondent was at all times & 31.5 & 32.0 & 31.8 \\
\hline Partner did not trust respondent with any money & 18.1 & 18.3 & 18.2 \\
\hline Partner pushed, shook, or threw something at respondent & 9.9 & 16.7 & 13.8 \\
\hline Partner slapped respondent & 16.3 & 18.8 & 17.8 \\
\hline Partner twisted respondent's arm or pulled her hair & 6.7 & 8.0 & 7.4 \\
\hline $\begin{array}{l}\text { Partner punched respondent with fist or with something that could hurt } \\
\text { her }\end{array}$ & 7.7 & 12.2 & 10.3 \\
\hline Partner kicked, dragged, or beat up respondent & 5.6 & 6.4 & 6.1 \\
\hline Partner tried to choke or burn respondent on purpose & 1.9 & 2.3 & 2.1 \\
\hline $\begin{array}{l}\text { Partner threatened or attacked respondent with a knife, gun or any } \\
\text { other weapon }\end{array}$ & 2.7 & 5.4 & 4.3 \\
\hline $\begin{array}{l}\text { Partner physically forced respondent to have sexual intercourse when } \\
\text { she did not want }\end{array}$ & 10.9 & 14.0 & 12.7 \\
\hline $\begin{array}{l}\text { Partner forced or performed any sexual acts that respondent did not } \\
\text { want }\end{array}$ & 10.9 & 8.9 & 9.8 \\
\hline Partner said or did something to humiliate respondent in front of others & 15.7 & 8.5 & 11.6 \\
\hline Partner threatened to hurt respondent or someone close to her & 9.6 & 10.7 & 10.2 \\
\hline Partner insulted respondent or made her feel bad about others & 19.2 & 16.7 & 17.8 \\
\hline Respondent experienced any of the above acts of violence & 60.0 & 65.8 & 63.4 \\
\hline Respondent sought help from anywhere after experiencing violence & $(\mathrm{N}=225)$ & $(\mathrm{N}=339)$ & $(N=564)$ \\
\hline No & 51.1 & 51.3 & 51.2 \\
\hline Yes & 37.3 & 28.9 & 32.3 \\
\hline No answer & 11.6 & 19.8 & 16.5 \\
\hline Reasons for not seeking help after experiencing violence ${ }^{a}$ & $(\mathrm{~N}=115)$ & $(\mathrm{N}=174)$ & $(\mathrm{N}=289)$ \\
\hline Too scared/ashamed & 22.6 & 21.3 & 21.8 \\
\hline Feared being embarrassed/stigmatized & 4.4 & 8.1 & 6.6 \\
\hline No money to seek help & 0.0 & 2.3 & 1.4 \\
\hline Did not think it was important/would help & 18.3 & 20.7 & 19.7 \\
\hline Did not think it was a serious matter & 49.6 & 52.3 & 51.2 \\
\hline Matter settled by family members/relatives & 7.8 & 6.3 & 6.9 \\
\hline Other & 15.7 & 8.1 & 11.1 \\
\hline Source of help after experiencing violence ${ }^{a}$ & $(\mathrm{~N}=84)$ & $(\mathrm{N}=98)$ & $(\mathrm{N}=182)$ \\
\hline Health facility/counseling center & 0.0 & 3.1 & 1.7 \\
\hline Social service organization & 1.2 & 0.0 & 0.6 \\
\hline Police/lawyer/local administration & 6.0 & 9.2 & 7.7 \\
\hline Religious leader & 2.4 & 1.0 & 1.7 \\
\hline Family members/relatives/in-laws & 78.6 & 90.8 & 85.2 \\
\hline Friends/neighbors & 29.8 & 11.2 & 19.8 \\
\hline Other & 2.4 & 0.0 & 1.1 \\
\hline
\end{tabular}


Less than half of the young mothers who experienced any form of intimate partner violence sought help ( $37 \%$ in urban and $29 \%$ in rural site) while about half (51\% in urban and a similar proportion in rural site) did not seek help from anywhere (Table 11). The most common reasons for not seeking help included not considering the experience a serious matter (50\% in urban and $52 \%$ in rural site), being too scared or ashamed (23\% in urban and $21 \%$ in rural site), not thinking that it was important or it would help (18\% in urban and $21 \%$ in rural site), and other reasons (16\% in urban and $8 \%$ in rural site) such as no reason or not seeing the need ( 9 cases), lack of someone or place to seek help from (6 cases), enduring the experience or feeling that it was normal ( 6 cases), and settling the matter among themselves ( 5 cases). The most common sources for those sought help were family members, relatives or in-laws (79\% in urban and $91 \%$ in rural site) and friends or neighbors (30\% in urban and $11 \%$ in rural site).

\section{Counseling and Psychosocial Support}

A total of 138 young mothers were counseled on various issues by professional counselors during data collection (68 in urban and 70 in rural site). The issues that the young mothers faced and on which they were counseled cut across the two sites and included dropping out of school, marital conflict (disagreements and neglect by partner), separation and divorce, death of parents, death of children, birth complications, poor pregnancy outcomes (abortion, miscarriage and stillbirth), poverty, sexual violence including rape, neglect by parents/guardians, early marriage, emotional and physical violence all of which characterize the experiences of young mothers that is evident from the results of the quantitative interviews. In the words of some counselors:

I met two girls aged 13 years who had the same issue of being rejected by their by parents. Their boyfriends convinced them to take pills in order to abort the pregnancy without consulting any doctor. At the end of the day, they found that they were losing everything: school, baby as well as good relationship with their family members, which affected them psychologically and resulted in them developing bad behavior.

(Counselor, Urban site)

A girl started crying [after being asked questions by the researcher] and she didn't want to talk. The researcher asked me to talk to her. She told me that, “I didn't plan to have a child at this age. This baby was not my plan. I was raped while going to fetch water. After that I didn't realize that I was pregnant until the teacher asked us to go to the hospital for check-up. That was the end of attending school and the beginning of taking care of my pregnancy and finally a baby. I am now living with my parents."

(Counselor, Rural site)

All counselors reported that the process had a positive impact on the girls. Some counselors indicated that the girls were happy after the counseling process based on expressions on their faces (smiling and making jokes). Other counselors reported that the girls verbally expressed appreciation after the process stating that from then on, they had renewed energy to move on with their lives regardless of what happened in the past. Some of the girls simply appreciated the fact that someone talked to them about their lives and the challenges they faced because at home no one was talking to them about the same apart from blaming them. A key challenge was that the counseling process was being conducted in the context of a study, which might not have allowed sufficient time to provide comprehensive counseling for the girls. However, the counselors referred the girls for further services to health facilities or social service organizations working in the respective areas. 


\section{Perspectives of Healthcare Providers}

Some of the factors mentioned by healthcare providers as contributing to early pregnancies and increased risk of HIV infection among young people were similar to those reported by the young mothers themselves. These included peer pressure, lack of information on preventive services, poor socio-economic conditions, unstable family backgrounds, and non-disclosure of HIV status to the child, which create conditions where girls are vulnerable to being induced or forced into unprotected sexual intercourse at an early age. Two other factors came up during interviews with providers. One was the issue of early marriage whereby after completion of primary education, most parents/guardians do not give priority to girls when making decisions regarding transitions to the next level of schooling because they would get married anyway. The second issue was cultural rites of initiation for girls especially in the rural setting where providers reported that when girls reach puberty, they are taken for traditional initiation where they are taught how to handle men, which leads to temptations to practice what they are taught.

There are many challenges. I managed to recognize two children at my place. One was living with her grandmother. She was twelve years. She was born with HIV. Her grandmother knew but she did not tell her. After some time she moved from [name of place] to [name of place] where she engaged in sexual intercourse. As a result, she got pregnant and gave birth to a baby boy without being tested if she was HIV-positive or negative. Then after one year she got sick and her condition deteriorated. She was tested and found with HIV. When they told her grandmother about the issue, she replied that, 'I knew it from the beginning, I didn't want to tell her'.

(Female provider, 43 years, urban site)

Here there is a tradition known as jando and unyago. These are traditions of the southern people...These jando and unyago do not help these young girls...at 8 or 9 years of age...they are taught nothing of any importance... they are taught how to handle a man while they are still young, so they want to practice what they are taught and that's when they end up getting pregnant.

(Female provider, 36 years, rural site)

The consequences of pregnancy among young girls mentioned by providers were also similar to those mentioned by the young mothers. These included dropping out of school, desertion by partner, being disowned by family members, psychosocial stress, deterioration in socio-economic conditions, and poor pregnancy outcomes including complications, abortion, miscarriage or stillbirth owing to their young age, not seeking appropriate care or doing so when it is too late, and lack of awareness about how to take care of themselves during pregnancy.

Yes, for example there is a girl aged 17 years who showed up today with a history of vaginal bleeding...I found out she was 17 years old as I was going through her card for treatment. She is in standard six and was deceived into having unprotected sex with somebody and got pregnant...After talking to her for long, she eventually told me that she was deceived by a man and agreed to go with him to his residence twice and got pregnant. She also stopped going to school...even today she came because of her mother. Although her mother accepted to take care of the pregnancy, she was still thinking about it since she has not yet completed standard seven.

(Female provider, 27 years, urban site)

When you compare the ones who got pregnant at a young age, you will see that they have been affected psychologically. They will not be free in their community...Also most of the young mothers aged between 12 and 19 years are abandoned after getting pregnant because the partners are also worried about how the community will perceive them. So, abandoning the mother means abandoning the child as well who will be brought up in a very difficult environment; they will not get the best care in terms of their health; they will not grow properly and they will not become physically fit and at the end of the day we are just increasing the number of dependents in the society.

(Female provider, 30 years, rural site)

Access to reproductive health and HIV care services by young mothers varied by facility even within the same setting (urban or rural), perhaps reflecting variations in the catchment populations of the respective facilities. Some providers reported large numbers of young mothers accessing either reproductive health or HIV 
services while others reported low numbers. Providers mentioned various challenges with young mothers accessing care some of which were similar to those reported by young mothers themselves. These included both individual- and facility-level factors. Individual-level factors were feeling of embarrassment, lack of information on available services, self-blame for the health conditions (either pregnancy or HIV infection), not considering the health condition a serious matter, non-disclosure of HIV status, and fear of being seen around counseling and testing centers (CTCs). Facility-level factors, on the other hand, included inappropriate timing of care (given that most young people were not comfortable being served together with adults), requirement for clients to be accompanied by their partners or parents/guardians, stock-outs of medicines and supplies, inadequate space and limited human resources.

Many times when a young girl discovers she is pregnant, she will first hide it. When they do report to our clinic, the pregnancy is a third trimester one; it is really a challenge. What we do is, we provide her with the services as we do for other pregnant women, except that we really like to have adequate involvement of the parents. For instance, last year we had a 13-year old pregnant child and we were able to have adequate involvement of her parent and later on we referred her for a Caesarean section delivery at [name of facility].

(Female provider, 32 years, urban site)

Most of them do come after getting pregnant but they don't feel free. They are usually not free because they got pregnant at a young age, and when they come to the clinic, adults look at them like she is just 14 years old and she has come to start clinic with a 36-year old woman. So, they are usually not free when they come and they are being insulted by some community members. So, that also contributes to lack of freedom to seek health services. So, you may ask them to come at a certain time for the next visit and they might not show up and when they come you ask them why didn't they show up for their last clinic visit and they just keep quiet.

(Female provider, 30 years, rural site)

Problems are many....because being pregnant at a young age has a risk of even losing life. Because at this age the body is not ready, it is being forced. Since the pregnancy has to remain a secret, no medical attention is received; as a result, there is a possibility of complications during delivery. And if found infected, it will be too late to prevent the unborn baby from HIV infection.

(Female provider, 38 years, rural site)

Providers reported applying various strategies to reach young people in general and young mothers in particular with reproductive health and HIV information and services. The strategies included separating the young people into groups based on age and tailoring the services appropriately; devising friendly ways of relating with them (one provider reported that they refer to young girls as 'cute girls' to encourage them to maintain positive attitudes towards life and avoid risky sexual behavior); initiating specific activities for young people to keep them busy (such as youth clubs); providing testing and pregnancy prevention information and services through outreach in the community and in schools; creating separate time for young people (e.g. outside of working hours or workplaces); door-to-door visits by home-based care providers (HBCs); and engaging parents/guardians. The other strategy that providers suggested could reduce young people's vulnerability to early pregnancy or HIV infection besides improving access to reproductive health and HIV services was the creation of socio-economic opportunities for them, especially for those who are out of school. However, none of the providers reported that they had such initiatives and the suggestion was more for the government to implement.

We have given them that name [cute girls] as a motivation to make them respond when we need them to come here. We needed to make efforts to attract them because when I came here I found many young girls getting pregnant and getting complications during delivery and I have seen some of them die. So, that is a reason for calling them cute girls because they feel proud and when they see me, they also call me cute aunt. So, I always tell them to protect themselves, to protect their beauty so that they can grow up and become successful people like doctors or nurses...Many girls come on their own asking for Depo-Provera. We probe them with a few questions about the connection between family planning and their age. But many have been used to me now, they have known I reserve time to serve them every after 13:00, so they don't come in the morning because 
they may meet someone familiar to them here and be stigmatized because they are too young to seek family planning services.

(Female provider, 52 years, urban site)

Because others come secretly, they come even outside of the workplace. Because already you are friends with them, they follow you to your home and you leave your activities to help them. Also, you help them to prevent problems because you find others fear their parents. And others don't want to be seen by other people going there [to facility]. When they come your home, they are seen to have come for a certain thing. They can visit you at home when they know there is no company, and you serve them.

(Female provider, 44 years, rural site) 


\section{Summary of Findings, Implications and Limitations}

\section{Summary of Findings}

Various vulnerabilities exposed the young mothers to early sexual debut and pregnancy: These included peer pressure, poor socio-economic conditions, unstable family backgrounds, lack of information on preventive services, early marriage, and cultural rites of initiation for young girls especially in the rural site. As a result, nearly all the young mothers (close to $100 \%$ in each site) were not attending school at the time of interview, largely because of poor performance (22\% in urban and $48 \%$ in rural site), lack of fees or learning materials (30\% in urban and $22 \%$ in rural site), completion of a given level of schooling (15\% in urban and $8 \%$ in rural site), and pregnancy or childbirth (16\% in urban and $4 \%$ in rural site). Moreover, less a quarter (21\%) of the mothers had secondary and above level of education (32\% in urban and 14\% in rural site). About one-third (30\%) of young mothers in the urban site lived with other relatives, followed by husband, partner or boyfriend (26\%), single biological parent (23\%), and both biological parents (18\%) while more than half $(54 \%)$ of the young mothers in the rural site lived with husband, partner or boyfriend, followed by both biological parents (18\%), single biological parent (14\%), and other relatives (11\%). For those in the urban site who were not living with both biological parents, 38 percent reported that one of their parents was dead, 27 percent indicated that their parents were divorced or separated while 26 percent were double orphans (both parents dead). Majority (48\%) of those in the rural site who were not living with both biological parents reported that their parents were divorced or separated, about one-third (32\%) indicated that both parents were dead while 18 percent were single orphans (one parent dead).

Majority of the young mothers had first sexual intercourse before age 18, with first sex being largely consensual in less stable relationships while most recent sex was in more stable relationships: About twothirds of young mothers in both sites had the first sexual intercourse between the ages of 15 and 17 years (63\% in urban and $66 \%$ in rural site) while 26 percent of those in the urban and 20 percent of those in the rural site had first sexual intercourse between the ages of 11 and 14 years. More than two-thirds of young mothers in either site had consensual first sex i.e. either or both partners wanted to have sexual intercourse (68\% in urban and $70 \%$ in rural site), with the first sexual partner being older than the respondent in most cases (62\% in urban and $64 \%$ in rural site). In both sites, the first sexual partner was mostly either a steady boyfriend/fiancé (46\% in urban and $38 \%$ in rural site) or friend/acquaintance (43\% in urban and $47 \%$ in rural site). The first sexual intercourse resulted in pregnancy for $16 \%$ of young mothers in the urban and seven percent of those in the rural site. A higher proportion of young mothers in the rural than in the urban areas had sexual intercourse in the past three months preceding the survey (53\% and 19\% respectively) and in nearly all the cases ( $98 \%$ in either site), either or both partners to have sexual intercourse. Similar to first sexual intercourse, the last sex was with an older partner (70\% in urban and $79 \%$ in rural site). Unlike first sexual intercourse, half (50\%) of young mothers in the urban site and 75 percent of those in the rural site had the last sex with a husband or live-in partner.

Use of a method to prevent pregnancy was higher during most recent than first sexual encounter, with variations in methods being used and source: A higher proportion of young mothers whose sexual encounters were not forced or a result of rape used a method to prevent pregnancy during most recent encounter (46\% in urban and $62 \%$ in rural site) than at first encounter (19\% in urban and 53\% in rural site). However, use of a method to prevent HIV or sexually transmitted infections (STIs) remained low during first (21\% in urban and $37 \%$ in rural site) or most recent sexual encounter (19\% in urban and $16 \%$ in rural site). The most commonly used method at first sex was condom (93\% in urban and $70 \%$ in rural site), with the source of method largely being shops or pharmacies/drug stores in the urban site (43\% and 39\% respectively) and shops, health facilities or pharmacies/drug stores in the rural site (41\%, 39\% and 19\% respectively). In contrast, the methods commonly used during last sex were condoms (38\% in urban and $24 \%$ in rural site), injectables (33\% in urban and $43 \%$ in rural site), implants (30\% in urban and $36 \%$ in rural site), and pills (11\% in urban and $2 \%$ in rural site), with health facilities were the predominant sources of a method used during last sex ( $67 \%$ in urban and $84 \%$ in rural site) 
Reasons for non-use of a method to prevent pregnancy or infection shifted from largely lack of knowledge during first sex to other factors during most recent sex: Among young mothers in the urban site who did not use a method to prevent pregnancy or HIV/STIs at first sex, the reasons given for non-use included lack of knowledge of methods (38\%), respondents not thinking that they would get pregnant (35\%), partner refusing to use a method (18\%), and lack of time to prepare (13\%). In the rural site, the most common reasons for non-use were lack of knowledge (29\%) and respondents not thinking that they would get pregnant (12\%). The most common reasons for non-use of a method during last sex among young mothers in the urban site were partner refusal (23\%), respondents not thinking that they would get pregnant (21\%), fear of side-effects (12\%), desire to get pregnant (11\%) and other reasons (36\%), largely that they trusted themselves or their partners. In the rural site, the most common reasons for non-use of a method during last sex were desire to get pregnant (26\%), respondents not thinking that they would get pregnant (25\%), and other reasons (22\%), mostly that they were already pregnant.

Although most young mothers had obtained information on prevention of pregnancy and HIV/STIs, they were not satisfied with the information they received: Most young mothers reported that they had received information on pregnancy prevention (78\% in urban and $85 \%$ in rural site) and prevention of HIV/STIs (82\% in urban and $70 \%$ in rural site). The most common source of information on the issues was healthcare providers/counselors (62\% in urban and $55 \%$ in rural site), followed by friends or peers (52\% in urban and $33 \%$ in rural site), teachers or guest speakers at school (42\% in urban and $21 \%$ in rural site), electronic media (30\% in urban and $13 \%$ in rural site), and parents/guardians ( $21 \%$ in urban and $14 \%$ in rural site) or other family members/relatives (10\% in urban and $15 \%$ in rural site). However, most (70\%) of the young mothers in the urban site and less than half (47\%) of those in the rural site were not satisfied with information on sexuality and reproductive health that they obtained from the mentioned sources although the majority were of the opinion that such information is appropriate for young girls of their age (95\% in urban and $85 \%$ in rural site). Ironically, the most preferred sources of such information among young mothers in the urban site were healthcare providers or facilities; mass media including print, electronic or social media; and community gatekeepers including religious leaders and community health volunteers while those in the rural site mostly preferred healthcare providers/facilities or family members/relatives. The reasons for preference of specific sources included ease of access, credibility or reliability of information from such sources, and confidentiality in the delivery of information. This suggests that the challenge could be more with the adequacy of information obtained than the source.

Majority of the young mothers got pregnant for the first time before age 18, with a higher proportion of pregnancies in urban than rural site being unintended: Majority of the young mothers got pregnant for the first time between the ages of 15 and 17 years (58\% in urban and $67 \%$ in rural site) while the proportion that got pregnant at ages 11-14 years was twice as high in the urban than in the rural site (12\% and $6 \%$ respectively). Most of the young mothers had been pregnant once ( $87 \%$ in urban and $92 \%$ in rural site). More than three-quarters (79\%) of the pregnancies in the urban site and 46 percent of those in the rural site were unintended. Variations in unintended pregnancy between sites could partly reflect the circumstances in which the pregnancies occurred. Pregnancies to young mothers in the urban site occurred when they were living with relatives (29\%), single biological parents (24\%), both biological parents (22\%) or husband/partner/boyfriend (22\%) while, majority (60\%) of pregnancies to young mothers in the rural site occurred when they were living with husband, partner or boyfriend. In addition, steady boyfriends or fiancés were responsible for 51 percent of the pregnancies in the urban site while husbands or live-in partners were responsible 56 percent of the pregnancies in the rural site. The major reason for not using a method to prevent unintended pregnancies in the urban site was lack of knowledge of methods or where to get them (43\%), followed by fear of side-effects (19\%), and respondents not thinking that they would get pregnant (17\%). The major reason in the rural site was lack of knowledge of methods or where to get them (25\%), followed by method failure or incorrect use (23\%), fear of side-effects (15\%), respondents not thinking that they would get pregnant (14\%), and other reasons (12\%) including being denied a method at facility (7 cases), fear of going to facility or using a method (3 cases), forgetting to use a method (3 cases), and services being too far (3 cases).

Various factors influenced poor pregnancy influenced poor pregnancy outcomes among young mothers who had such experiences: The proportion of pregnancies that resulted in wastage (miscarriage, stillbirth or 
abortion) was nearly twice as high in the urban as in the rural site (17\% and $10 \%$ respectively). Eleven percent of pregnancies in either site resulted in Caesarean section while the majority were normal deliveries ( $87 \%$ in urban and $89 \%$ in rural site). Nineteen percent of pregnancies in the urban site and 16 percent of those in the rural site resulted in complications, with the common types of complications being bleeding, convulsions, problems walking, stomach pains, less blood or water in the body, and prolonged healing of Caesarean scar. Findings from in-depth interviews with young mothers showed that poor pregnancy outcomes were due to pre-existing health conditions (such HIV infection, STIs, and high blood pressure), psychological stress associated with unintended pregnancy, no or late initiation of clinic visits, delayed decision-making at the household level to seek care (due to lack of resources or influence of grandparents), intimate partner violence, suspicion of foul play in cases of extended families, lack of relevant services or supplies at facility, long distance to alternative facilities, poor means of transport (use of motorcycles), poor treatment by providers (especially female nurses), and not being provided with appropriate care.

Access to reproductive health and HIV services varied by type of care: Young mothers sought in either site sought antenatal care for most of the pregnancies (84\% in urban and $93 \%$ in rural site). However, the proportion of pregnancies for which mothers obtained PMTCT services was lower than for antenatal care (34\% in urban and $52 \%$ in rural site). Most deliveries in either site occurred in a health facility ( $86 \%$ in urban and $85 \%$ in rural site) under a skilled provider i.e. doctor, nurse or midwife ( $86 \%$ in urban and $85 \%$ in rural site). In addition, mothers sought care at a facility for about two-thirds (62\%) of delivery-related complications that occurred in the urban site and 85 percent of those in the rural site. Mothers also sought health checkup after delivery or pregnancy termination for more than half $(57 \%)$ of the pregnancies in the urban site and less than half (46\%) of the pregnancies in the rural site. In addition, mothers sought health check-up from a healthcare provider for most of the babies who were born alive (93\% in urban and $82 \%$ in rural site). Less than half of the babies in either site were tested for HIV (45\% in urban and $38 \%$ in rural site), with three percent of babies in the urban site and one percent of those in the rural site whose mothers shared test results being HIV-positive. Interviews with service providers showed that access to reproductive health and HIV care services by young mothers varied by facility even within the same setting (urban or rural), perhaps reflecting variations in the catchment populations of the respective facilities.

Various factors influenced young mothers' access to reproductive health or HIV services: In-depth interviews with young mothers who did not seek care from a health facility showed that some of the reasons included lack of information on available services, circumstances in which the pregnancy occurred (such as forced sex or very young age) which led to feeling of embarrassment, being disowned by parents or partner, poor socio-economic conditions, the requirement at the facility to be accompanied by a partner, abrupt or early occurrence of pregnancy wastage (abortion, miscarriage or stillbirth occurring too soon after conception), and perceived poor treatment by healthcare providers. In addition, quantitative interviews showed that feeling of embarrassment, partner refusal, delays in decision-making to seek care, distance to facility (especially in the rural site), lack of supplies or services at a facility, and not considering the health condition a serious issue as other reasons for not seeking care. Being HIV-negative and lack of awareness about HIV status were additional reasons for not obtaining PMTCT services while abrupt labor or labor occurring at night or during weekends when facilities were closed were other reasons for not seeking delivery care.

Pregnancies to young mothers were more likely to result in negative than positive consequences in cases where mothers reported experiencing life changes: Among young mothers who reported experiencing life changes as a result of pregnancy and childbirth, the most common consequences were worsening of economic status; worsening of health status; and being mocked by family members, friends or neighbors. Only a small fraction of pregnancies to young mothers in either site resulted in positive life changes such as improvements in health or economic status. Findings from in-depth interviews with young mothers showed that being disowned by family members or partner, loss of sense of worth, dropping out of school, psychological stress, and worsening socio-economic conditions were some of the consequences of getting pregnant at an early age.

Majority of young mothers reported experiencing intimate partner violence during pregnancy although few sought help: About two-thirds (65\%) of the young mothers reported experiencing at least one form of intimate partner violence during a pregnancy (63\% in urban and $67 \%$ in rural site). In addition, mothers experienced 
intimate partner violence for 60 percent of the pregnancies in the urban and 66 percent of the pregnancies in the rural site. Less than half of the young mothers who experienced any form of intimate partner violence sought help (37\% in urban and $29 \%$ in rural site) while about half (51\%) in urban and a similar proportion in rural site) did not seek help from anywhere. The most common sources for those sought help were family members, relatives or in-laws ( $79 \%$ in urban and $91 \%$ in rural site) and friends or neighbors (30\% in urban and $11 \%$ in rural site). Reasons for not seeking help included not considering the experience a serious matter ( $50 \%$ in urban and $52 \%$ in rural site), being too scared or ashamed ( $23 \%$ in urban and $21 \%$ in rural site), not thinking that it was important or it would help (18\% in urban and $21 \%$ in rural site), and other reasons such as not seeing the need (9 cases), lack of someone or place to seek help from (6 cases), enduring the experience or feeling that it was normal ( 6 cases), and settling the matter among themselves ( 5 cases).

Providers employed various strategies to reach young people in general and young mothers in particular with reproductive health and HIV information and services: The strategies included separating the young people into groups based on age and tailoring the services appropriately; devising friendly ways of relating to them; initiating specific activities for young people to keep them busy (such as youth clubs); providing testing and pregnancy prevention information and services through outreach in the community and in schools; creating separate time for young people (e.g. outside of working hours or workplaces); door-to-door visits by HBCs; and engaging parents/guardians.

\section{Implications}

- The vulnerabilities that expose young people to early sexual debut, early pregnancy, and the risk of HIV infection suggest the need for reaching them with appropriate information before they start engaging in risky sexual behavior. One strategy which some of the healthcare providers alluded to is to target them while they are still in school. Such a strategy requires creating strong linkages between the education health sectors in order to ensure that provision of information in schools is by professionals given that teachers may be ill-equipped to offer accurate information.

- Individual-level factors that contribute to non-use of services and poor pregnancy outcomes among young mothers such as lack of awareness about available services, low risk perceptions regarding the chances of getting pregnant or being infected, psychological stress resulting from experiencing unintended pregnancy, and feelings of embarrassment and loss of sense of self-worth can be addressed through appropriate information, education and communication (IEC) campaigns in communities and health facilities.

- Non-use of services and poor pregnancy outcomes among young mothers that result from householdlevel influences such as poverty, unstable families, and intimate partner violence suggest the need for a combination of strategies that involve community sensitization and investments geared towards improving livelihoods at the local level.

- Facility-level influences on use of services and pregnancy outcomes among young mothers such as inconvenient times, requirement for clients to be accompanied by their partners or parents/guardians, stock-outs of medicines and supplies, poor interpersonal relations on the part of providers, inadequate space, and limited human resources require interventions aimed at strengthening the health systems to adequately respond to service needs of young people.

\section{Study Limitations}

One potential limitation of the study arises from the purposive identification and selection of participants (young mothers and healthcare providers). It could be that the process led to the inclusion in the study of those with specific experiences (in the case of young mothers) or opinions (in the case of healthcare providers). In addition, the study was conducted in only two districts. The findings cannot therefore generalized to all young mothers or healthcare providers in Tanzania. Young mothers were further asked to recall specific experiences during each of the pregnancies they had ever had. Experiences with pregnancies occurring farther back from the interview date could be affected by recall bias. 


\section{References}

Aarø, L.E., A.J. Flisher, S. Kaaya, H. Onya, M. Fuglesang, K.I. Klepp, and H. Schaalma. 2006. "Promoting sexual and reproductive health in early adolescence in South Africa and Tanzania: development of a theoryand evidence based intervention programme." Scandinavian Journal of Public Health 34(2):150-158.

Becher, Heiko, Olaf Müller, Albrecht Jahn, Adjima Gbangou, Gisela Kynast-Wolf, and Bocar Kouyaté. 2004. "Risk factors of infant and child mortality in rural Burkina Faso." Bulletin of the World Health Organization 82(4):265-273.

Biddlecom, Ann, Richard Gregory, Cythia B. Lloyd, and Barbara S. Mensch. 2008. "Associations between premarital sex and leaving school in four sub-Saharan African countries." Studies in Family Planning 39(4):337-350.

Bongaarts, John and Steven W. Sinding. 2011. "Family planning as an economic investment." SAIS Review XXXI(2): 35-44.

Clark, Shelley. 2004. "Early marriage and HIV risks in sub-Saharan Africa." Studies in Family Planning 35(3):149-160.

Eloundou-Enyegue, Parfait M. 2004. "Pregnancy-related drop-outs and gender inequality in education: A lifetable approach and application to Cameroon." Demography 41(3):509-528.

Grant, Monica J. and Kelly K. Hallman. 2008. "Pregnancy-related school dropout and prior school performance in KwaZulu-Natal, South Africa." Studies in Family Planning 39(4):369-384.

Hokororo, Adolfine, Abert F. Kihunrwa, Samuel Kalluvya, John Changalucha, Daniel W. Fitzgerald, and Jennifer A. Downs. 2015. "Barriers to access reproductive healthcare for pregnant adolescent girls: a qualitative study in Tanzania." Acta Paediatrica doi 10.1111/apa.12886.

llika, Amobi and Igwegbe Anthony. 2004. "Unintended pregnancy among unmarried adolescents and young women in Anambra State, South East Nigeria." African Journal of Reproductive Health 8(3):92-102.

Katz, Karen and Christine Naré. 2002. "Reproductive health knowledge and use of services among young adults in Dakar, Senegal." Journal of Biosocial Science 34(2):215-231.

Klima, Carrie S. 1998. "Unintended pregnancy: Consequences and solutions for a worldwide problem." Journal of Nurse-Midwifery 43(6): 483-491.

Lloyd, Cynthia B., Barbara S. Mensch, and Barbara Mensch. 2008. "Marriage and childbirth as factors for dropping out of from school: An analysis of DHS data from sub-Saharan Africa." Population Studies 62(1):113.

Luke, Nancy. 2003. "Age and economic asymmetries in the sexual relationships of adolescent girls in subSaharan Africa." Studies in Family Planning 34(2):67-86.

Mamboleo, Neema. 2012. Unwanted pregnancy and induced abortion among female youths: a case study of Temeke district. Unpublished Dissertation.

Manzini, Ntsiki. 2001. "Sexual initiation and childbearing among adolescent girls in KwaZulu Natal, South Africa." Reproductive Health Matters 9(17):44-52.

McCleary-Sills, J, Z. Douglas, A. Rwehumbiza, A. Hamisi, and R. Mabala. 2013. "Gendered norms, sexual exploitation and adolescent pregnancy in rural Tanzania." Reproductive Health Matters 21(41):97-105. doi: 10.1016/S0968-8080(13)41682-8.

Ministry of Education and Vocational Training [Tanzania]. 2013. Dropout due to pregnancy in mainland Tanzania: Basic education statistics in Tanzania. Dar es Salam: Ministry of Education and Vocational Training. 
National Bureau of Statistics (NBS) [Tanzania] and ICF Macro. 2011. Tanzania Demographic and Health Survey 2010. Dar es Salaam, Tanzania: NBS and ICF Macro.

National Bureau of Statistics (NBS) [Tanzania]. 2012. 2012 Population and Housing Census: Population Distribution by Age and Sex. Dar es Salaam: NBS.

Okereke, Chukwunenye Iheanacho. 2010. "Assessing the prevalence and determinants of adolescents' unintended pregnancy and induced abortion in Owerri, Nigeria." Journal of Biosocial Science 42(5):619-632.

Population Council, Tanzania Commission for AIDS (TACAIDS), Zanzibar AIDS Commission (ZAC), and UNICEF Tanzania. 2015. The Adolescent Experience In-Depth: Using Data to Identify and Reach the Most Vulnerable Young People, Tanzania 2009-2012. Dar es Salaam: Population Council, TACAIDS, ZAC and UNICEF Tanzania.

Population Reference Bureau. 2014. 2014 World Population Data Sheet. Washington, DC: PRB.

Rasch, Vibeke, and Rose Kipingili. 2009. "Unsafe abortion in urban and rural Tanzania: method, provider and consequences." Tropical Medicine and International Health 14(9):1128-1133.

Republic of Kenya. 2012. Violence against Children in Kenya: Findings from a 2010 National Survey. Summary Report on the Prevalence of Sexual, Physical and Emotional Violence, Context of Sexual Violence, and Health and Behavioral Consequences of Violence Experienced in Childhood. Nairobi: United Nations Children's Fund Kenya Country Office, Division of Violence Prevention, National Center for Injury Prevention and Control, U.S. Centers for Disease Control and Prevention, and the Kenya National Bureau of Statistics.

Reynolds, Heidi W., Emelita L. Wong, and Heidi Tucker. 2006. "Adolescents' use of maternal and child health services in developing countries." International Family Planning Perspectives 32(1):6-16.

Singh Susheela, Gilda Sedgh, and Rubina Hussain. 2010. “Unintended pregnancy: worldwide levels, trends and outcomes." Studies in Family Planning 41(4):241-250.

Tylee, Andre, Dagmar M. Haller, Tanya Graham, Rachel Churchill, Lena A. Sanci. 2007. "Youth-friendly primary-care services: how are we doing and what more needs to be done?" Lancet 369(9572):1565-1573.

Ubora wa Afya kwa Familia Duniani. 2001. Adolescent sexual and reproductive health: report on an assessment and review of training materials. Dar es Salaam: Ubora wa Afya kwa Familia Duniani.

UNAIDS (Joint United Nations Programme on HIV/AIDS). 2014. United Republic of Tanzania: developing subnational estimates of HIV prevalence and the number of people living with HIV. Geneva: UNAIDS.

Varga, Christine A. 2003. "How gender roles influence sexual and reproductive health among South African adolescents." Studies in Family Planning 34(3):160-172.

Warenius, Linnéa U., Elisabeth A. Faxelid, Petronella N. Chishimba, Joyce O. Musandu, Antony A. Ong'any, and Eva B-M. Nissen. 2006. "Nurse-midwives' attitudes towards adolescent sexual and reproductive health needs in Kenya and Zambia." Reproductive Health Matters 14(27):119-128.

WHO [World Health Organization]. 2011a. Early marriages, adolescent and young pregnancies. Report by the Secretariat. Available at: http://apps.who.int/gb/ebwha/pdf files/WHA65/A65 13-en.pdf. [Accessed on August 8, 2014].

WHO [World Health Organization]. 2011b. Unsafe abortion: Global and regional estimates of the incidence of unsafe abortion and associated mortality in $2008,6^{\text {th }}$ edition. Geneva: WHO.

Wood, Kate and Rachel Jewkes. 2006. "Blood blockages and scolding nurses: Barriers to adolescent contraceptive use in South Africa." Reproductive Health Matters 14(27):109-118.

Wright, Daniel, Mary L. Plummer, Gerry Mshana, Joyce Wamoyi, Zachayo S. Shigongo, and David A. Ross. 2006. "Contradictory sexual norms and expectations for young people in rural Northern Tanzania." Social Science \& Medicine 62(4):987-997. 